\title{
The Rb/E2F pathway: expanding roles and emerging paradigms
}

\author{
J. William Harbour ${ }^{1,2}$ and Douglas C. Dean ${ }^{1,3}$ \\ ${ }^{1}$ Division of Molecular Oncology and ${ }^{2}$ Department of Ophthalmology and Visual Sciences, Washington University, \\ St. Louis, Missouri 63110,USA
}

Received April 21, 2000; revised version accepted July 17, 2000.

The retinoblastoma gene was identified over a decade ago as the first tumor suppressor. Although the gene was initially cloned as a result of its frequent mutation in the rare pediatric eye tumor, retinoblastoma (Friend et al. 1986; Fung et al. 1987; Lee et al. 1987), it is now thought to play a fundamental role in cellular regulation and is the target of tumorigenic mutations in many cell types. The retinoblastoma gene encodes a 928-amino acid phosphoprotein, $\mathrm{Rb}$, which arrests cells in the $\mathrm{G}_{1}$ phase (Weinberg 1995). Rb is phosphorylated and dephosphorylated during the cell cycle; the hyperphosphorylated (inactive) form predominates in proliferating cells, whereas the hypophosphorylated (active) form is generally more abundant in quiescent or differentiating cells (Chen et al. 1989). As a demonstration its tumor suppressor activity, $\mathrm{Rb}$ was reintroduced into $\mathrm{Rb}$-deficient tumor cells and it blocked several features of the malignant phenotype (Huang et al. 1988). Mutations affecting the retinoblastoma gene are frequently encountered, not only in retinoblastoma but also in other cancers such as osteosarcoma, small cell lung cancer, prostate cancer, and breast cancer (Friend et al. 1986; Fung et al. 1987; Harbour et al. 1988; Lee et al. 1988; T'Ang et al. 1988; Bookstein et al. 1990). Indeed, children with hereditary retinoblastoma have $\geq 30$-fold increased risk of developing a second, nonocular malignancy, especially bone and soft tissue sarcomas in adolescence and cutaneous melanomas in adulthood (Eng et al. 1993; Moll et al. 1997). These second neoplasms occur almost exclusively in patients who have germ-line mutations in the retinoblastoma gene. As a further indication of its fundamental role in tumor suppression, $\mathrm{Rb}$ can be functionally inactivated by constitutive hyperphosphorylation in tumors that do not have mutations in the retinoblastoma gene (Sherr 1996). In addition, DNA tumor viruses express oncoproteins, such as adenovirus E1A, SV40 large tumor antigen, and human papillomavirus (HPV) E7, that bind and inactivate

${ }^{3}$ Corresponding author.

E-MAIL ddean@im.wustl.edu; FAX (314) 747-2797.

Article and publication are at www.genesdev.org/cgi/doi/10.1101/ $\operatorname{gad} .813200$.
$\mathrm{Rb}$; these proteins are required for the viruses to transform cells (DeCaprio et al. 1988; Whyte et al. 1988; Dyson et al. 1989).

$\mathrm{Rb}$ function depends, at least in part, on interactions with the E2F family of DNA-binding transcription factors (E2F) (Chellappan et al. 1991; Dyson 1998; Nevins 1998). E2F sites are found in the promoters of many genes that are important for cell cycle progression, and $\mathrm{Rb}$ appears to repress transcription of these genes through its interaction with E2F (Blake and Azizkhan 1989; Thalmeier et al. 1989; Dalton 1992; Ohtani et al. $1995)$. Recent findings in the $\mathrm{Rb} / \mathrm{E} 2 \mathrm{~F}$ field are clarifying how this pathway regulates the transition from $G_{1}$ to $S$ phase at the molecular level. Other emerging results show that this pathway also regulates other parts of the cell cycle and that it may even have roles beyond cell cycle control. In this article, we review the current understanding of the mechanism of action of $\mathrm{Rb}$ and its roles in cell cycle regulation, apoptosis, and development. We refer readers to recent reviews by Bartek et al. (1997), Dyson (1998), Lipinski and Jacks (1999), and Sherr and Roberts (1999) for additional in-depth analysis of the field and for historical perspectives.

\section{Rb structure}

$\mathrm{Rb}$ contains several functional domains. Domains A and $\mathrm{B}$ are highly conserved from humans to plants, and they interact with each other along an extended interdomain interface to form the central "pocket" (Chow and Dean 1996; Lee et al. 1998), which is critical to the tumorsuppressor function of $\mathrm{Rb}$ (Qin et al. 1992). The pocket is disrupted by most naturally occurring germ-line mutations in hereditary retinoblastoma patients (Harbour 1998) and by most tumor-derived mutations (Horowitz et al. 1990). Viral oncoproteins and a number of endogenous $\mathrm{Rb}$-binding proteins contain an LXCXE motif that allows them to bind $\mathrm{Rb}$ (Whyte et al. 1988; Dyson et al. 1989; Ludlow et al. 1989; Lee et al. 1998). The crystal structure of the pocket in complex with an LXCXE peptide revealed that the binding site for LXCXE is in domain B (Lee et al. 1998). However, domain A is required 
for domain B to assume an active conformation, thus explaining the conservation of both domains (Kim and Cho 1997; Lee et al. 1998). A number of endogenous proteins that interact with $\mathrm{Rb}$ also contain an LXCXElike sequence, including histone deacetylase (HDAC)-1 and HDAC2, and the ATPase, BRG1, from the SWI/SNF nucleosome remodeling complex (Dunaief et al. 1994; Brehm et al. 1998; Luo et al. 1998; Magnaghi et al. 1998).

The LXCXE binding site is the best characterized but not the only binding site in the pocket. E2Fs do not contain an LXCXE and thus bind $\mathrm{Rb}$ at a distinct site that appears to involve points of contact in both the pocket and in the carboxy-terminal region (Huang et al. 1992; Lee et al. 1998). This allows E2F to recruit complexes containing $\mathrm{Rb}$ and other proteins, such as those with the LXCXE motif, to a promoter. Still other binding sites appear to be in the pocket. Whereas HDAC1 and HDAC2 contain LXCXE-like motifs through which they can interact with $\mathrm{Rb}$ (Magnaghi et al. 1998), HDAC3 does not contain this sequence, and mutations in the LXCXE binding site of $\mathrm{Rb}$ do not affect its binding to $\mathrm{Rb}$ (Chen and Wang 2000; Dahiya et al. 2000). Although BRG1 contains an LXCXE, it does not require this sequence to bind $\mathrm{Rb}$, which allows $\mathrm{Rb}$ to recruit BRG1 and HDAC1 into a single complex (Zhang et al. 2000). Three recent studies in which the LXCXE-binding site was mutated have provided additional, albeit somewhat conflicting, insights into its role. In each of these studies, the mutations inhibited binding to E1A. In two of the studies the mutations also inhibited binding to HDAC1 and HDAC2 but did not affect binding to HDAC3, BRG1, and E2F1 (Chen and Wang 2000; Dahiya et al. 2000). In the third study mutations did not affect binding to HDAC1 (N. Dyson, pers. comm.). Because mutation of the LXCXE-binding site had variable effects on $\mathrm{Rb}$ function in these studies, further work is needed to clarify its role and to characterize other binding sites on $\mathrm{Rb}$.

Another functional domain of $\mathrm{Rb}$ is located within the carboxy-terminal region. This region contains binding sites for the c-abl tyrosine kinase and MDM2, which appear to be distinct from the E2F site in the carboxyterminal region (Welch and Wang 1993; Xiao et al. 1995). The tyrosine kinase activity of c-abl is blocked when it is complexed with Rb (Welch and Wang 1993). This interaction appears to be important for Rb-mediated growth suppression (Whitaker et al. 1998). When $\mathrm{Rb}$ is hyperphosphorylated, active c-abl is released (Welch and Wang 1993). In addition to directly blocking c-abl, the carboxyterminal region also appears to participate in the assembly of multimeric complexes containing Rb, E2F, c-abl, and potentially, other proteins. These complexes seem to be required for $\mathrm{Rb}$ function (Welch and Wang 1995). The importance of the Rb-MDM2 interaction is less clear. MDM2 interacts with the p53 tumor suppressor protein and opposes its proapoptotic activity by repressing p53 transcriptional activation and by mediating its degradation (Haupt et al. 1997; Kubbutat et al. 1997). Although initial results showed that MDM2 blocks $\mathrm{Rb}$ function, more recent studies have shown that $\mathrm{Rb}$ can form a trimeric complex with MDM2 and p53 and thereby block the antiapoptotic activity of MDM2 by preventing the degradation of p53 (Hsieh et al. 1999). Further work is needed to elucidate the role of these protein interactions involving the carboxy-terminal region of $\mathrm{Rb}$ in vivo.

The function of the amino-terminal region of $\mathrm{Rb}$ remains controversial. This region contains consensus cdk phosphorylation sites, which may regulate $\mathrm{Rb}$ activity when they are phosphorylated during the cell cycle. In addition, the amino-terminal region interacts with several proteins, including MCM7 (a replication licensing factor; Sterner et al. 1998), a novel $\mathrm{G}_{2} / \mathrm{M}$ cycle-regulated kinase (Sterner et al. 1995), and other proteins (Durfee et al. 1994), but the function of these interactions is still unclear. In experiments with genetically engineered mice lacking $\mathrm{Rb}$, introduction of an $\mathrm{Rb}$ transgene with an amino-terminal truncation mutation delayed the embryonic lethality caused by homozygous loss of $\mathrm{Rb}$ but did not prevent it, suggesting that this region may be important for complete $\mathrm{Rb}$ function during development (Riley et al. 1997). Similarly, this Rb mutant did not prevent the development of pituitary tumors in $\mathrm{Rb}^{+/-}$ mice, although the onset of tumors was delayed, suggesting that this region may play some role in $\mathrm{Rb}$-mediated tumor suppression (Riley et al. 1997). However, these experiments relied on expression of an $\mathrm{Rb}$ transgene that may not entirely recapitulate the expression pattern and protein level of endogenous $\mathrm{Rb}$. In other experiments, tumor suppression by $\mathrm{Rb}$ was actually enhanced when the amino-terminal region was removed (Qin et al. 1992; Xu et al. 1994; Chow et al. 1996). Thus, a physiologic role of the amino-terminal region remains unclear and may only be settled once this region of the $\mathrm{Rb}$ gene is deleted in mice.

\section{Rb-mediated inhibition of E2F}

$\mathrm{Rb}$ can repress transcription by at least two different mechanisms. First, it can bind transcription factors such as E2F and block their ability to activate transcription (Flemington et al. 1993; Helin et al. 1993). Second, the $\mathrm{Rb}-\mathrm{E} 2 \mathrm{~F}$ repressor complex that forms at promoters can actively repress transcription (Bremner et al. 1995; Sellers et al. 1995; Weintraub et al. 1995). The balance between these two activities in vivo is still in question. In this section, we address the potential mechanisms through which $\mathrm{Rb}$ might inactivate E2F.

Because $\mathrm{Rb}$ binds E2F within its transactivation domain (Flemington et al. 1993; Helin et al. 1993), it was assumed initially that it physically blocks E2F transactivation. This idea is supported by in vitro studies in which $\mathrm{Rb}$ inhibited transcriptional activation by E2F1 in the apparent absence of other corepressors (Ross et al. 1999). However, Rb may also inhibit E2F by recruiting chromatin remodeling enzymes, including the HDACs mentioned above. The HDACs are a family of at least seven different enzymes that remove acetyl groups from the tails of histone octamers, which appears to facilitate condensation of nucleosomes into chromatin. This, in turn, inhibits gene expression by blocking access of tran- 
scription factors to the promoter (Kingston and Narlikar 1999; Kornberg and Lorch 1999; Wolffe and Hayes 1999). In contrast to experiments in vitro, transfection assays in cultured cells have suggested that interaction with HDAC is required for the inhibition of E2F1 by $R b$ (Brehm et al. 1998; Magnaghi et al. 1998). Other studies have only shown a partial requirement for HDAC activity in the Rb-mediated inhibition of E2F activity (Luo et al. 1998; Lai et al. 1999a). E2F1 has been shown to interact with the histone acetyl transferases p300/CBP and p/CAF (Trouche et al. 1996). Thus, it is possible that $\mathrm{Rb}$-mediated recruitment of HDAC to E2F acts to offset this histone acetyltransferase (HAT) activity (Fig. 1). It has also been shown recently that E2F1 can be acetylated, which increases the binding of the E2F/DP complex to DNA (Martinez-Balbas et al. 2000). Therefore, recruitment of $\mathrm{HDAC}$ to $\mathrm{E} 2 \mathrm{~F}$ via $\mathrm{Rb}$ may inhibit $\mathrm{E} 2 \mathrm{~F}$ activity by deacetylation of the protein, thereby inhibiting its binding to DNA (Fig. 1).

$\mathrm{Rb}$ can also interact with BRG1 and BRM-the two ATPase components of the human SWI/SNF chromatin remodeling complex, which is discussed in more detail below (Dunaief et al. 1994; Singh et al. 1995). Some results have shown that overexpression of BRG1/BRM can facilitate Rb-mediated inhibition of E2F1transcriptional activity (Trouche et al. 1997); however, other studies have found that E2F activity is inhibited efficiently in cells that are BRG1/BRM deficient (Weintraub et al. 1992; Zhu et al. 1993; Zhang et al. 2000). Thus the relative importance in vivo of these two potential mechanisms for inhibiting E2F transactivation-direct binding and masking of the E2F transactivation domain versus $\mathrm{Rb}$-mediated recruitment of chromatin remodeling enzymes to inhibit E2F-is still unclear.

\section{Active transcriptional repression by $\mathbf{R b}$}

Binding of $\mathrm{Rb}$ and other pocket proteins to E2F does not simply inhibit E2F activity. The resulting Rb-E2F com-

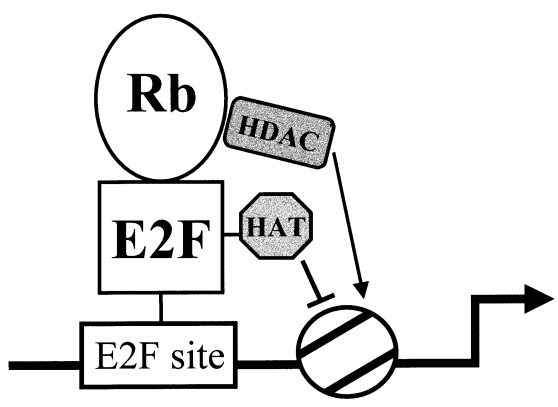

Figure 1. Potential roles of histone acetyltransferase (HAT) activity and histone deacetylase (HDAC) activity in regulating E2F activity. A cellular gene promoter with E2F-binding sites is depicted. HAT activity associated with E2F can promote binding of E2F to the promoter and it can inhibit nucleosome formation, thereby allowing further access of transcription factors to the promoter (see text). In contrast, HDAC recruited by $\mathrm{Rb}$ E2F appears to promote nucleosome assembly on the promoter, blocking access to transcriptional machinery. plex binds to promoters and actively represses transcription by blocking the activity of surrounding enhancers on the promoter (Weintraub et al. 1992; Hsiao et al. 1994; Johnson et al. 1994; Adnane et al. 1995; Bremner et al. 1995; Neuman et al. 1995; Sellers et al. 1995; Weintraub et al. 1995; Chow et al. 1996; Ferreira et al. 1998; Meloni et al. 1999). Whereas $\mathrm{Rb}$ requires sequences in the pocket and in the carboxy-terminal region to bind and inhibit $\mathrm{E} 2 \mathrm{~F}$, the pocket alone is sufficient for active repression when $\mathrm{Rb}$ is tethered directly to a promoter (e.g., through a Gal4 DNA binding domain; Bremner et al. 1995; Sellers et al. 1995; Weintraub et al. 1995). This is explained by the recent finding that active repression by $\mathrm{Rb}$ is attributable, at least in part, to the recruitment of pocketbinding corepressors. Perhaps the best studied of these corepressors are the chromatin remodeling enzymes.

Modification of chromatin structure is an important mechanism for regulating gene transcription (Felsenfeld 1992; Kingston and Narlikar 1999). One manner in which chromatin structure can be altered is by acetylation of histones. HATs have been shown to act as transcriptional coactivators that alter chromatin structure, thereby allowing transcription factors access to the promoter. In contrast, HDACs have been associated with transcriptional inhibition and are found in corepressor complexes (Alland et al. 1997; Grunstein 1997; Hassig and Schreiber 1997; Hassig et al. 1997; Heinzel et al. 1997; Laherty et al. 1997). Three of the seven known HDACs (HDAC1-HDAC3) interact with $\mathrm{Rb}$, and $\mathrm{Rb}$ can bind simultaneously to HDAC and E2F, allowing recruitment of an HDAC-Rb-E2F repressor complex at promoters of cell cycle genes (Brehm et al. 1998; Luo et al. 1998; Magnaghi et al. 1998; Lai et al. 1999a; Chen and Wang 2000; Dahiya et al. 2000). In two recent studies, Rb mutants that have amino acid substitutions in the LXCXE-binding site showed reduced binding to HDAC1 and HDAC2, but not HDAC3 (Chen and Wang 2000; Dahiya et al. 2000). The impaired interaction with HDAC1 and HDAC2 had no effect on the ability of the $\mathrm{Rb}$ mutants to inhibit transcriptional activation by E2F, but these mutants were unable to actively repress some genes and unable to maintain growth arrest. In addition, it has been shown that recruitment of an HDAC-Rb-E2F complex can actively repress transcription and regulate histone acetylation at the promoter (Luo et al. 1998). Furthermore, inhibition of HDAC with trichostatin A prevented repression of a set of cellular genes, including cyclin E, by Rb (Luo et al. 1998; Zhang et al. 2000). Together, these results suggest that HDAC activity has an important role in $\mathrm{Rb}$ function. In further support of this, results in Caenorhabditis elegans suggest that $\mathrm{Rb}$, HDAC, and RbAp48 antagonize the Ras signaling pathway in vulval precursor cells by repressing transcription of genes that are required for determining the fates of vulval cells (Lu and Horvitz 1998). In addition, RbAp48 has recently been shown to be a component of the $\mathrm{Rb}-\mathrm{HDAC}$ complex in mammalian cells (Nicolas et al. 2000).

Chromatin structure is also regulated through ATPdependent nucleosome remodeling complexes (Tyler and 
Kadonaga 1999). These complexes appear to influence the access of transcription factors to promoters by altering nucleosomal structure and the position of nucleosomes in a manner dependent on ATP hydrolysis (Schnitzler et al. 1998; Lorch et al. 1999). The first of these complexes to be identified was yeast SWI/SNF. Whereas all of the SWI/SNF-like complexes are made up of multiple subunits, each contains an ATPase that is central to its function. The ATPases in yeast SWI/SNF are SWI2/SNF2. A number of studies have suggested that SWI/SNF is important for transcriptional activation and that it is associated with recruitment of transcriptional activators and HAT activity (Cosma et al. 1999; Tyler and Kadonaga 1999). In a recent study, however, mutation of SWI2/SNF2 activated more genes than it repressed, suggesting that the SWI/SNF complex may be involved in transcriptional repression as well as activation (Holstege et al. 1998).

The human homologs of SWI2/SNF2 are BRG1 and BRM, which are capable of remodeling mononucleosomes as purified proteins in vitro (Phelan et al. 1999). Both proteins can interact with $\mathrm{Rb}$ (Dunaief et al. 1994; Singh et al. 1995), which suggests that they may have a role in $\mathrm{Rb}$ function. It is interesting that $\mathrm{Rb}$ can bind simultaneously to BRM and E2F, suggesting that a SWI/ SNF-Rb-E2F complex can form at promoters with E2F binding sites (Trouche et al. 1997). It has been shown that overexpression of BRG1 arrests cells that are deficient in BRG1 and BRM; this arrest is dependent on interaction with functional Rb (Dunaief et al. 1994). Expression of a dominant-negative form of BRG1 or BRM containing a mutant ATPase domain blocked growth suppression by Rb (Dunaief et al. 1994; Strobeck et al. 2000). Expression of BRG1 was also essential for $R b$ to growth arrest C33a cells, which are $\mathrm{Rb}^{-}$and BRG1/BRM deficient (Strobeck et al. 2000; Zhang et al. 2000). Furthermore, in a genetic screen for modifiers of a dE2F1 overexpression phenotype in the Drosophila eye, enhancer mutations included alleles of brahma, moira, and osa (homologs of SWI1, SWI2, and SWI3, respectively), suggesting that SWI/SNF chromatin-remodeling activity is important for negatively regulating $\mathrm{dE} 2 \mathrm{~F} 1$ function in flies (Staehling-Hampton et al. 1999). Taken together, the above findings suggest a role for both HDAC and SWI/SNF nucleosome remodeling complexes in $\mathrm{Rb} / \mathrm{E} 2 \mathrm{~F}$ function. Indeed, recent results indicate that $\mathrm{Rb}$ can recruit HDAC and SWI/SNF together into a single complex (Zhang et al. 2000).

How might these two classes of chromatin remodeling enzymes cooperate to regulate transcription? With activation of the HO gene in yeast, recruitment of SWI/SNF precedes recruitment of HAT activity to the HO gene promoter (Cosma et al. 1999). It is unclear whether SWI/ SNF recruitment is also an initial step in repression. However, it is possible that initial nucleosome remodeling by SWI/SNF is required for HAT to efficiently acetylate histones and to fix nucleosomes in an inactive state (Kingston and Narlikar 1999). Because virtually all transcription factors seem to interact with the p300/CBP coactivator, which has HAT activity, the default state on many promoters may be a balance in favor of HAT activity. Recruitment of SWI/SNF under such conditions would normally be associated with transcriptional activation. The Kingston group found that SWI/SNF can mediate a reversible reaction, causing continuous oscillation of nucleosomes between an active and inactive state (Fig. 2; Schnitzler et al. 1998). For repression to occur at the promoter in this model, SWI/SNF may need to bring along HDAC to alter the balance in the vicinity of the SWI/SNF complex in favor of HDAC activity (Fig. 2). Thus removal of acetyl groups by HDAC would unfix nucleosomes, forcing SWI/SNF-dependent reassembly of functional nucleosomes.

Other results have also suggested a role for $\mathrm{Rb}$ in transcriptional activation. In one study, $\mathrm{Rb}$ potentiated activation by the glucocorticoid receptor in a manner dependent on $\mathrm{Rb}$ interaction with BRM (Singh et al. 1995). Because the glucocorticoid receptor has been associated with HAT activity (Wallberg et al. 1999), one possibility is that transcriptional activation in this setting is a result of recruiting $\mathrm{Rb}-\mathrm{SWI} / \mathrm{SNF}$ to the glucocorticoid receptor where HAT activity is predominant. Transcriptional activation by $\mathrm{Rb}$ has also been implicated in differentiation. $\mathrm{Rb}$ is required for MyoD transactivation and thus its ability to induce myogenic differentiation /Gu et al. 1993). Some studies have suggested that this differentiation function of $\mathrm{Rb}$ involves direct transcriptional activation and does not require it to bind to E2F (Sellers et al. 1998). Might the roles for Rb in transcriptional activation all be mechanistically linked? This is still unclear,

Figure 2. Potential interplay among SWI/SNF, $\mathrm{HAT}$, and HDAC in transcriptional regulation. Kingston and coworkers have shown that SWI/SNF can remodel nucleosomes. It is important to note that this is a reversible reaction that is at least as efficient at assembling nucleosomes as it is at disrupting nucleosomes (for detailed review, see Kingston and Narlikar 1999). In this model, SWI/

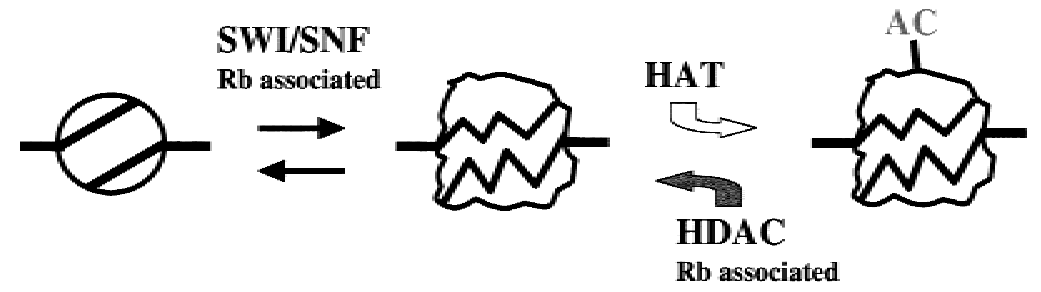
SNF ensures continuous oscillation of nucleosomes between a functional and disrupted structure. It is this disrupted nucleosome that may be targeted by HAT, which fixes the nucleosome in an inactive conformation, thereby driving the equation to the right. Conversely, recruitment of HDAC removes the inhibitory acetylation (AC), dumping unfixed disrupted nucleosomes back into the equation thereby forcing SWI/SNF to assemble them back into functional nucleosomes (moving the equation to the left toward function nucleosomes). Thus it is the balance between HDAC and HAT activity in the vicinity of SWI/SNF that determines whether SWI/SNF will facilitate transcriptional repression or activation. 
and thus, the molecular role of $\mathrm{Rb}$ in transactivation must be further examined.

Several studies have suggested that $\mathrm{Rb}$ can also actively repress transcription by HDAC-independent mechanisms (Luo et al. 1998; Meloni et al. 1999). These mechanisms may involve other corepressors such as CtIP, RBP1, and HBP1 (Yee et al. 1998; Lai et al. 1999a; Meloni et al. 1999). CtIP interacts with CtBP, so named because it binds to the carboxy-terminal region of adenovirus E1A (Schaeper et al. 1998). The Drosophila homo$\log$ of $\mathrm{CtBP}$ is a transcriptional corepressor for Hairy, Knirps, and Snail (Nibu et al. 1998). CtIP binds the Rb pocket and has intrinsic repressor activity. This activity requires the PLDLS sequence, which mediates interaction with CtBP (Meloni et al. 1999). RBP1 is another pocket-binding protein that has transcriptional repressor activity, inhibits E2F transactivation, and suppresses cell growth when it is overexpressed (Lai et al. 1999b). RBP1 contains two repression domains, one of which binds HDAC, whereas the other domain appears to function independent of HDAC. Thus, it is possible that RBP1 may recruit HDAC to the $\mathrm{Rb}$ pocket for HDAC-dependent active repression (although an HDAC-RBP1-Rb complex has not yet been demonstrated), and it may also mediate HDAC-independent repression through the second repression domain (Lai et al. 1999a). HBP1 is a transcriptional repressor belonging to the high-mobility group family of proteins. It has two LXCXE sequences and it has been shown that interaction with either $\mathrm{Rb}$ or p130 is required for it to repress the $N-M Y C$ promoter (Yee et al. 1998; Lipinski and Jacks 1999). The function and relative contributions of these various corepressors that interact with $\mathrm{Rb}$ family members must still be defined in vivo.

\section{$\mathrm{Rb}$ inhibition of $\mathrm{E} 2 \mathrm{~F}$ versus active repression by the Rb/E2F complex in cell cycle control}

A number of studies have shown that transcriptional activation by E2F is important for the progression of cells through the cell cycle (Johnson et al. 1993), suggesting that $\mathrm{Rb}$ arrests cells in $\mathrm{G}_{1}$ by inhibiting E2F transcriptional activity (Zhu et al. 1993; Qin et al. 1995). In this model, pocket proteins bind and inactivate $E 2 F$ in $G_{0}$ and early $G_{1}$, but as the pocket proteins are phosphorylated by cdks in mid-to-late $G_{1}$, free E2F is released, and it drives the cell into $S$ phase. Many of these studies have relied on overexpression of $\mathrm{E} 2 \mathrm{~F}$, which could also have the effect of competitively replacing the $\mathrm{Rb} / \mathrm{E} 2 \mathrm{~F}$ repressor complex on promoters with free E2F. Thus it is unclear in many of these studies whether the cells entered $\mathrm{S}$ phase as a result of transactivation by free E2F or displacement of the active $\mathrm{Rb} / \mathrm{E} 2 \mathrm{~F}$ repressor complex (or both). Studies using a dominant-negative mutant of the E2F-binding partner, DP1, inhibited the progression of cells into S phase (Wu et al. 1996), supporting the idea that interaction of E2F/DP with promoters is important for cell cycle progression. However, DP has binding partners other than E2F and it may have E2F-independent functions (Sorensen et al. 1996; de la Luna et al. 1999).
Most studies in which E2F genes have been deleted in mice have thus far failed to yield clear-cut evidence that transactivation is the primary function of E2F in cell cycle regulation, undoubtedly at least in part because of redundancy and functional compensation among the E2F family members. However, in one recent study, embryo fibroblasts derived from E2F3 gene knockout mice were delayed in entering S phase (Humbert et al. 2000). However, it is unclear whether this proliferative defect was present in the whole mouse or if this may be an E2F3dependent stress response on the part of the cells to being placed in culture. Nevertheless, these studies show evidence of a major cellular defect in the E2F3-/- cultured cells, and thus provide a critical tool for further examination of the role of E2Fs in vivo.

In tumors triggered by expression of $\mathrm{T}$ antigen, which binds $\mathrm{Rb}$ and $\mathrm{p} 53$ and releases free E2F, backcrossing the mice into an $\mathrm{E} 2 \mathrm{~F} 1^{-/-}$background-impaired tumor growth (Symonds et al. 1994). These results suggest that tumor growth depends on the free E2F1 that is released when $\mathrm{Rb}$ function is blocked by $\mathrm{T}$ antigen. Nevertheless, E2F1 does not seem to be required for essentially normal embryonic development. This suggests that free E2F1 may become essential for tumor cells because of their rapid growth relative to normal cells. However, this does not appear to be the case during development, when cells proliferate very rapidly, suggesting that E2F1 is not essential for rapid cell proliferation per se. Nevertheless, this may still explain the tumor-cell dependence on $\mathrm{E} 2 \mathrm{~F} 1$. In addition, crossing $\mathrm{Rb}^{-/-}$mice into an $\mathrm{E} 2 \mathrm{~F} 1^{-/-}$ background significantly reduced ectopic cell cycle entry in the CNS and lens compared to $\mathrm{Rb}^{-/-}$littermates (Tsai et al. 1998), providing evidence that release of free E2F1 can induce cells that would normally remain quiescent to enter the cell cycle.

It is interesting to consider the possibility that free E2F1 provides the tumor cells /and cells in the lens and CNS) with a growth advantage beyond simply shortening $\mathrm{G}_{1}$. Clearly, overexpression of E2F1 can drive serumstarved cells in $G_{0}$ into $G_{1}$. In this situation, the growthpromoting function of E2F1 negates the requirement for mitogens and drives quiescent growth-factor-starved cells into the cycle. Therefore, it is conceivable that the excess free E2F1 that is released by $\mathrm{T}$ antigen binding to $\mathrm{Rb}$ might similarly serve to reduce dependence on growth factors and provide tumor cells with a proliferative advantage under adverse conditions in which growth factors may be limiting (a situation that is common early in tumor progression). This could also provide lens and CNS cells with a growth factor-like boost from $G_{0}$ into $G_{1}$ under conditions in which the cells would normally remain quiescent.

Taken together, there is abundant evidence from overexpression assays in cultured cells and in several mouse models to support a role for transcriptional activation by E2F in regulation of the transition from $G_{1}$ to $S$ phase. However, this role needs to be further examined by dominant-negative, gene knockout, and other genetic approaches that do not rely on overexpression of E2F or forcing serum-deprived cells in $\mathrm{G}_{0}$ into the cell cycle. 
There is also growing evidence from recent studies that E2F forms an active repressor complex with $\mathrm{Rb}$ (and other pocket proteins) and that this complex is important for regulation of the cell cycle by $\mathrm{Rb}$ (Sellers et al. 1995; Zhang et al. 1999; He et al. 2000). In one study, plasmids containing multiple E2F-binding sites were used to titrate $\mathrm{Rb}-\mathrm{E} 2 \mathrm{~F}$ repressor complexes and to prevent their interaction with promoters (He et al. 2000). These competitor plasmids were able to prevent arrest in $\mathrm{G}_{1}$ following accumulation of endogenous hypophosphorylated $\mathrm{Rb}$. In a second study, a dominant-negative mutant of E2F1, which contained the DNA-binding domain but lacked the $\mathrm{Rb}$-binding site and transactivation domain, was used to displace Rb-E2F complexes from E2F-responsive genes. Expression of this E2F mutant prevented $\mathrm{Rb}$-dependent arrest of $\mathrm{G}_{1}$ by either p16 or TGF- $\beta$ (Zhang et al. 1999). However, overexpression of $\mathrm{Rb}$ (in contrast to activation of endogenous $\mathrm{Rb}$ ) still caused arrest of $G_{1}$ in the presence of this dominant-negative E2F, suggesting that artificially high levels of $\mathrm{Rb}$ can arrest cells in an E2F-independent (and potentially nonphysiologic) fashion. Taken together, such studies show that active repression by $\mathrm{Rb}-\mathrm{E} 2 \mathrm{~F}$ has an important role in growth suppression by Rb. However, these studies do not show that E2F does not have a role in transcriptional activation in the cell cycle-it is unclear from either of these studies whether or not binding of free E2F to endogenous promoters was eliminated. Therefore, it is still unclear how this active repression by Rb/E2F contributes to control of the cell cycle in vivo relative to $\mathrm{Rb}$ mediated inhibition of transcriptional activation by free E2F. Perhaps a current consensus view may be that the switch from active transcriptional repression by $\mathrm{Rb} / \mathrm{E} 2 \mathrm{~F}$ family complexes to activation by free E2F is important and it provides a mechanism for efficient regulation of cell cycle genes.

A role for E2F may be forthcoming from work in Drosophila. Two E2Fs have been identified in DrosophiladE2F1 contains a transactivation domain, whereas dE2F2 does not (Dynlacht et al. 1994; Ohtani and Nevins 1994; Duronio et al. 1995; N. Dyson, pers. comm.). Mutation of $d E 2 F 1$ led to a defect affecting the entry of cells into $S$ phase, suggesting that its transactivation function may be important for driving cells into $S$ phase. However, it is also conceivable that with mutation of $d E 2 F 1$, a higher percentage of dE2F2 becomes complexed with Drosophila $\mathrm{Rb}$ proteins (RBF1 and RBF2), leading to an accumulation of repressor complexes and arrest of cells in $\mathrm{G}_{1}$. Mutation of $d E 2 F 1$ or $d E 2 F 2$ led to embryonic defects, and crossing the mutants should provide genetic insight into the general role of $\mathrm{dE} 2 \mathrm{~F}$.

\section{Regulation of $\mathbf{R b}$ function by phosphorylation}

Cell cycle progression normally occurs when $\mathrm{Rb}$ is inactivated by phosphorylation catalyzed by cdks in complex with their cyclin partners (Chen et al. 1989; Hinds et al. 1992; Lundberg and Weinberg 1998). Rb contains 16 potential sites for cdk phosphorylation, and it oscillates between hypophosphorylated and hyperphosphorylated forms during the cell cycle. At least three different cyclin-cdk complexes have been suggested to phosphorylate $\mathrm{Rb}$ during the cell cycle. It is thought that cyclin D-cdk4/6 phosphorylates Rb early in $G_{1}$, cyclin E-cdk2 phosphorylates the protein near the end of $\mathrm{G}_{1}$, and cyclin A-cdk2 may maintain phosphorylation of $\mathrm{Rb}$ during $\mathrm{S}$ phase (Sherr 1996). Phosphorylation of specific sites appears to regulate distinct $\mathrm{Rb}$ functions, suggesting complex regulation of $\mathrm{Rb}$ by these phosphorylation events. For example, binding of E2F, LXCXE proteins, and c-abl are regulated by distinct sets of phosphorylation sites (Knudsen and Wang 1996, 1997). Adding to the complexity, recent studies have suggested that $\mathrm{Rb}$ is unphosphorylated and inactive in $\mathrm{G}_{0}$, and that initial phosphorylation by cdk4/6 leads to a hypophosphorylated, active protein (Ezhevsky et al. 1997). Subsequent hyperphosphorylations by cdk4/6 later in $G_{1}$ are then thought to inhibit $\mathrm{Rb}$ function. These results highlight the complexity of $\mathrm{Rb}$ phosphorylation events and our lack of a detailed understanding of this process.

Most of the studies of $\mathrm{Rb}$ phosphorylation have relied on overexpression of cyclins and/or cdks, so it is still unclear which cyclin-cdks normally phosphorylate $\mathrm{Rb}$ in vivo. Nevertheless, there appears to be a consensus that $\mathrm{Rb}$ can be phosphorylated sequentially by different cdks during the cell cycle. In one study, successive phosphorylation by cyclin D-cdk4/6 and cyclin E-cdk2 was necessary to completely hyperphosphorylate $\mathrm{Rb}$ (Lundberg and Weinberg 1998). It is interesting, however, that a "knockin" of the cyclin E gene into the cyclin D1 gene locus in mice prevented at least some of the phenotypic manifestations of the cyclin D1 gene deletion, suggesting that cyclin $\mathrm{E}$ is a downstream target of cyclin D1 function (Geng et al. 1999). If this is indeed the case, then why would $\mathrm{Rb}$ need to be phosphorylated by both cyclin D-cdk4/6 and cyclin E-cdk2? Recently, a mechanistic explanation was suggested for how cyclin D-cdk4/6 and cyclin E-cdk2 may regulate distinct $\mathrm{Rb}$ functions (Harbour et al. 1999). In this study, cyclin D-cdk4/6 appears to phosphorylate specific phosphoacceptor sites in the carboxy-terminal region of $\mathrm{Rb}$, and this triggers an intramolecular interaction between the phosphorylated carboxy-terminal region and a positively charged "lysine patch" encircling the LXCXE-binding site in domain B of the pocket. This interaction displaces HDAC from the pocket, and it was proposed that this inhibits the ability of $\mathrm{Rb}$ to repress the cyclin $\mathrm{E}$ gene (Harbour et al. 1999; Zhang et al. 1999). Overexpression of cyclin E is sufficient to overcome growth arrest induced by a phosphorylation-resistant $\mathrm{Rb}$ mutant, $\mathrm{Rb} \Delta \mathrm{cdk}$ (Leng et al. 1997; Lukas et al. 1997), indicating that cyclin E-cdk2 has a critical target or targets in the Rb pathway other than $\mathrm{Rb}$ itself. Taken together, the above studies provide support for a model wherein $\mathrm{Rb}$ regulates the sequential expression of cyclins as the cell cycle progresses. Cyclin D-cdk4/6 allows expression of cyclin E by disrupting the Rb-HDAC complex (Harbour et al. 1999; Zhang et al. 2000), and then cyclin E expression is sufficient to overcome Rb-imposed arrest of $G_{1}$ (Zhang et al. 2000). Such a model could explain why cyclin D-cdk4/6 might not 
be necessary for cell cycle progression if cyclin $\mathrm{E}$ is expressed constitutively or prematurely during the cell cycle.

The cyclin D-cdk4/6-dependent intramolecular interaction between the carboxy-terminal region of $\mathrm{Rb}$ and the pocket not only inhibits HDAC-mediated repression by $\mathrm{Rb}$, it also appears to recruit cyclin E-cdk2 to the pocket through RXL docking sites located in the carboxy-terminal region (Adams et al. 1999; Harbour et al. 1999|. This recruitment of cyclin E-cdk2 then facilitates phosphorylation of Ser 567, an otherwise inaccessible phosphoacceptor site buried within the domain A-domain B interface (Harbour et al. 1999). Ser 567 makes critical contacts between domain A and B (Lee et al. 1998), and this phosphorylation disrupts the A-B interface and blocks Rb binding to E2F. The sensitive location of Ser 567 is further illustrated by the fact that it is the only potential cdk phosphoacceptor site in $\mathrm{Rb}$ that is a target of naturally occurring missense mutations in tumors (Templeton et al. 1991). However, this phosphorylation of Ser 567 has been shown only in vitro, and it is not yet clear whether it actually occurs in vivo or if it is the only target of cyclin E-cdk2 on Rb in the absence of cyclin/cdk overexpression. It is also important to point out that these studies have relied on cyclin overexpression to activate endogenous cdks, which could lead to elevated levels of cdk activity and altered specificity. In addition, these studies were performed in tumor cells, which may not display a normal cell cycle. Nevertheless, such studies have provided evidence that phosphorylation of Rb by successive cyclin-cdk complexes can progressively block the interaction of $\mathrm{Rb}$ with regulatory proteins, which is consistent with the notion that different phosphorylated forms of $\mathrm{Rb}$ have distinct roles during the cell cycle (see below).

\section{Roles for $R b$ beyond $G_{1}$ phase}

Although it is widely accepted that $\mathrm{Rb}$ arrests cells in $\mathrm{G}_{1}$, there is growing evidence that it also has regulatory effects on the cell cycle beyond $\mathrm{G}_{1}$. Microinjection of a phosphorylation-resistant $\mathrm{Rb}$ mutant blocked DNA synthesis in cells that had passed the $G_{1}$ restriction point, suggesting that $\mathrm{Rb}$ can inhibit progression of the cell cycle beyond $G_{1}$ (Knudsen et al. 1998). In other experiments, the arrest of $G_{1}$ imposed by ectopic expression of either p16 or a phosphorylation-resistant $\mathrm{Rb}$ could be overcome by coexpression of cyclin $\mathrm{E}$, resulting in completion of $S$ phase and the remainder of the cell cycle (Lukas et al. 1997). In addition, this cyclin E-induced S phase did not require E2F transactivation, suggesting that cyclin $\mathrm{E}$ can act downstream from $\mathrm{Rb} / \mathrm{E} 2 \mathrm{~F}$. What then could be the downstream target of cyclin E-cdk2 in the Rb pathway? One possible target is the BRG1 component of SWI/SNF. Cyclin E has been found to associate with BRG1 and to inhibit growth arrest induced by BRG1 (Shanahan et al. 1999). Also, BRG1 is phosphorylated in a cell cycle-dependent fashion (Sif et al. 1998), and this phosphorylation inhibits SWI/SNF function
(Shanahan et al. 1999). Because SWI/SNF function appears to be required for growth suppression by $\mathrm{Rb}, \mathrm{BRG} 1$ could serve as an important downstream target of cyclin E-cdk2 in the Rb/E2F pathway. Thus cyclin E in S phase may play a major role in the inhibition of SWI/SNF.

A recent study supports this idea and provides evidence that $\mathrm{Rb}$ regulates progression through $\mathrm{S}$ phase via its interaction with SWI/SNF (Zhang et al. 2000). In this study, evidence is presented that an HDAC-Rb-SWI/ SNF complex is required to inhibit cyclin E expression and to prevent entry into $S$ phase (Fig. 3). Phosphorylation of $\mathrm{Rb}$ by cyclin $\mathrm{D}-\mathrm{cdk} 4 / 6$ inhibited $\mathrm{Rb}$ binding to HDAC, but not to BRG1. The persisting Rb-SWI/SNF complex allowed accumulation of cyclin E-cyclin E-cdk2 is required for assembly of origins of DNA replication and thus for S phase (Krude et al. 1997), but cyclin A and cdc2 genes remained inhibited. It is unclear whether an HDAC-independent corepressor is required for this Rb-SWI/SNF-mediated inhibition of the cyclin A gene. It is then proposed that the resulting increase in cyclin E levels leads to inactivation of the Rb-SWI/SNF complex by cyclin E-cdk2, through its phosphorylation of $\mathrm{Rb}$ and/or BRG1. However, this was not directly shown in the studies. This inactivation of Rb-SWI/SNF is suggested to allow the accumulation of cyclin A and cdc2. But, it is unclear whether this is a direct effect on the cyclin A promoter, and the link between $\mathrm{Rb}-\mathrm{SWI} /$ SNF and cyclin A expression is still somewhat circumstantial. It is interesting that the $\mathrm{Rb}-\mathrm{SWI} / \mathrm{SNF}$ complex could not arrest cells in $\mathrm{G}_{1}$ when $\mathrm{Rb}-\mathrm{HDAC}$ activity was diminished, but the complex could still inhibit cells from exiting $S$ phase. These cells also underwent endoreduplication with $>4 \mathrm{~N}$ DNA content. It has been suggested that this abnormality was attributable to Rb-SWI/ SNF-mediated inhibition of cdc2 and cyclin A, which are required for activation of cyclin $\mathrm{B}-\mathrm{cdc} 2$ and $\mathrm{M}$ phase. Although cyclin A and cdc2 levels did decrease in these experiments, it has not yet been shown that these are the only targets of $\mathrm{Rb}-\mathrm{SWI} / \mathrm{SNF}$ and that they are responsible for the effect. However, in this regard it is interesting that a link between $\mathrm{Rb} / \mathrm{E} 2 \mathrm{~F}$ and cyclin $\mathrm{B}-\mathrm{cdc} 2$ was recently established (Lukas et al. 1999). Results have shown that the anaphase promoting complex (APC), a

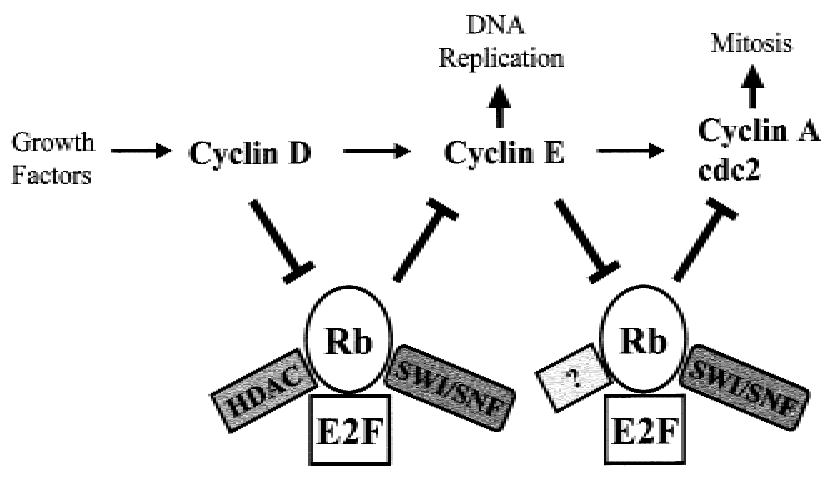

Figure 3. Potential roles for different Rb-chromatin remodeling complexes during the cell cycle. (?) Potential unknown corepressor. (See text for details.) 
ubiquitin ligase that causes the degradation of cyclin B, remains active in the cell into $S$ phase (Brandeis and Hunt 1996). APC depresses the level of cyclin B until cyclin A-cdk2 phosphorylates the Cdh1 subunit of the complex, blocking its activity and thereby allowing accumulation of cyclin B near the end of S phase-formation of cyclin B-cdc2 is then required for entry into mitosis. This process was shown to be controlled by Rb/E2F inhibition of the cyclin A gene (Fig. 4) (Lukas et al. 1999).

The HDAC and SWI/SNF studies described above have relied heavily on the C33A cell line, which is $\mathrm{Rb}^{-}$and deficient in BRG1/BRM. Although HDAC readily forms complexes with $\mathrm{Rb}$ and Mad when proteins are overexpressed in these cells, these complexes are not capable of efficiently repressing transcription (Zhang et al. 2000). This was critical for allowing examination of various $\mathrm{Rb}$-repressor complexes in some degree of isolation. However, it is important to emphasize that these studies have thus far been restricted to tumor cell lines and that they need to be reproduced in more normal cells and in genetic models. As pointed out to us by a reviewer, we had originally listed C33A among the different cell lines that we had used to examine Rb-HDAC activity (Luo et al. 1998). This was an oversight on our part (the Saos-2 cell line should have been listed in these studies in place of C33A) - in fact the C33A cells show only very limited evidence of $\mathrm{Rb}$ - or Mad-HDAC activity (Zhang et al. 2000 ), and they have been very useful in analyzing RbSWI/SNF activity for this reason. Despite diminished levels of BRM/BRG1 and the inability to form an efficient $\mathrm{Rb}-\mathrm{HDAC}$ repressor complex, $\mathrm{Rb}$ still represses some promoters (e.g., the SV40 promoter/enhancer) in $\mathrm{C} 33 \mathrm{~A}$ cells, suggesting that $\mathrm{Rb}$ may interact functionally

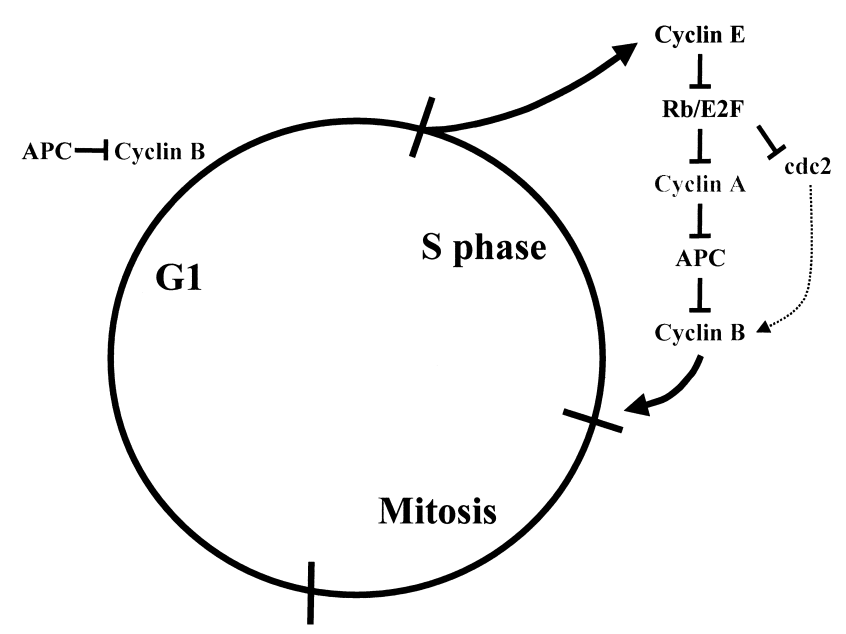

Figure 4. A novel link between cyclin A-cdk2, the anaphase promoting complex (APC), and assembly of cyclin B-cdc2. Recent studies from Bartek and coworkers suggest that cyclin A-cdk2 phosphorylates a component of the anaphase promoting complex, APC, blocking activity of the ubiquitin ligase which normally inhibits cyclin B expression (Lukas et al. 1999). These studies suggest that $\mathrm{Rb} / \mathrm{E} 2 \mathrm{~F}$ and cyclin $\mathrm{A}-\mathrm{cdk} 2$ have roles in regulation of APC and formation of cyclin B-cdc2, which is required for entry into mitosis. with yet another corepressor such as CtIP/CtBP, RBP1, HBP1, or an unidentified factor.

The results described above suggest an intricate relationship between Rb/E2F and cyclin/cdks, which may serve at least in part to maintain the sequential order of cyclin/cdk activity during the cell cycle and regulate the exit of cells from $G_{1}$ and $S$ phase. However, it is important to point out that the relative significance of these $\mathrm{G}_{1}$ and $\mathrm{S}$ phase checkpoints in $\mathrm{Rb}$ function in vivo has yet to be established. And, although it has been shown that $\mathrm{BRG} 1 / \mathrm{BRM}$ is required in $\mathrm{Rb}$ growth suppression using dominant-negative BRG1 and BRM, which does not rely on overexpression assays, there are still questions that need to be addressed before such a model for $\mathrm{Rb}$ function with HDAC and SWI/SNF can be fully accepted. For example, association of HDAC, SWI/SNF, and $\mathrm{Rb}$ family members must be examined during the cell cycle without protein overexpression, and association of these complexes with endogenous promoters must be evaluated during the cell cycle to determine if the effects are actually direct. In addition, the components of this potential pathway need to be evaluated in a genetic system in which their interplay can be examined in vivo. In this regard, further analysis of the Rb-E2F pathway in Drosophila and C. elegans, where initial genetic screens have implied roles for both SWI/SNF- and HDAC-like components in the pathway, must be pursued.

In Drosophila, dE2F1 appears to play a role in regulation of the localization of origin of replication complex (ORC) and in DNA replication (Royzman et al. 1999). Ovarian follicle cells in Drosophila undergo four endoreduplication cycles, after which there is additional amplification of the chorion genes to produce sufficient protein for the eggshell. A dE2F1 mutant that is truncated after the DNA-binding domain and thus lacks an $\mathrm{Rb}$ binding domain or transactivation domain leads to both premature and excessive amplifications in the follicle cells, suggesting that this process may be negatively regulated by an $\mathrm{Rb} / \mathrm{E} 2 \mathrm{~F}$ complex (which cannot form with the mutant). Such a complex could regulate ORC activity by at least two mechanisms. First, it may recruit chromatin-remodeling enzymes to the origins, promoting nucleosome assembly and thereby physically blocking replication. However, dE2F has not yet been localized to the amplification origins. Alternatively, dE2F/ RBF may actively repress expression of a component of the ORC complex. Indeed, ORC1 has been shown to be transcriptionally regulated by E2F in both Drosophila and in human cells (Ohtani et al. 1996; Asano and Wharton 1999). It is then possible that the regulation of exit from $S$ phase in human cells by Rb/E2F complexed with chromatin-remodeling enzymes that has been observed in cultured cells (Zhang et al. 2000) may be occurring via direct effects on DNA replication or through control of expression of an ORC component.

\section{Roles for $\mathbf{R b}$ in apoptosis}

$\mathrm{Rb}$ is inactivated either by mutation or by hyperphosphorylation in many tumors. Such a loss of Rb function 
can trigger a p53-dependent apoptotic pathway, which may serve as an intrinsic protective mechanism to eliminate cells in which the $\mathrm{Rb}$ pathway is deregulated (Morgenbesser et al. 1994). Accordingly, loss of $\mathrm{Rb}$ function may also create a survival pressure for the cell to acquire mutations in this apoptotic pathway, thus explaining the high apoptotic index that is often found in $\mathrm{p} 53^{+}$tumors and the frequent mutation of p53 in cancer (Symonds et al. 1994). A link between $\mathrm{Rb}$ and p53 appears to be the free $\mathrm{E} 2 \mathrm{~F} 1$, which is released when $\mathrm{Rb}$ function is lost. In support of this idea, transgenic mice in which $\mathrm{Rb}$ was inactivated developed slowly growing tumors of the choroid plexus with high apoptotic rates, whereas the additional inactivation of p53 led to rapidly growing tumors at least in part because of an $85 \%$ reduction in apoptosis (Symonds et al. 1994). Concomitant deletion of the E2F1 gene (instead of p53 inactivation) led to an $80 \%$ reduction in p53-dependent apoptosis in mice in which $\mathrm{Rb}$ was inactivated (Pan et al. 1998). In addition, Rb-deficient mice die in midgestation with widespread apoptosis (Clarke et al. 1992; Jacks et al. 1992; Lee et al. 1992), whereas embryos that are mutants for both Rb and E2F1 show a significant reduction in apoptosis and down-regulation of the p53 pathway (Tsai et al. 1998). Taken together, these results suggest that release of free E2F1 resulting from loss of $\mathrm{Rb}$ function is responsible for triggering much of this p53-dependent apoptosis. How does this free E2F1 trigger p53-dependent apoptosis? A potential target of free E2F1 is the ARF gene (the alternate reading frame encoded by the p16INK4a locus; Bates et al. 1998). One function of ARF appears to be inhibition of MDM2-mediated turnover of p53, which in turn leads to an increase in p53 and apoptosis (Fig. 5) (Pomerantz et al. 1998; Zhang et al. 1998). Although it appears that E2F1 can activate ARF directly in overexpression assays (DeGregori et al. 1997) and that E2F1-dependent negative selection of thymocytes is associated with ARF expression (Zhu et al. 1999) it is still unclear whether or not this is a primary mechanism through which free E2F triggers apoptosis in vivo. Thus further studies are needed to define the mechanism of E2F1-induced apoptosis. Previous studies have suggested that E2F1 is somewhat unique among the E2F family members in its ability to trigger apoptosis (DeGregori et al. 1997). However, more recent studies now suggest that other E2F family members can also trigger apoptosis, and that this activity is regulated by their subcellular localization (Loughran and La Thangue 2000).

If $\mathrm{Rb}$ is hyperphosphorylated by cyclin $\mathrm{D}-\mathrm{cdk} 4 / 6$ and cyclin E-cdk2 and free E2F is released as cells progress through $\mathrm{G}_{1}$ into $S$ phase, then why does this not free E2F trigger apoptosis? One possibility is that release of free E2F during the cell cycle is not sufficient to trigger an apoptotic response because another required pathway is not activated under these conditions (e.g., accumulation of free E2F is not sufficient for the apoptosis). This does not seem likely given that overexpression of E2F is sufficient to trigger the apoptotic response in cells and that a significant portion of the apoptosis resulting from mutation of the $\mathrm{Rb}$ gene is alleviated when the mice are crossed into an $\mathrm{E} 2 \mathrm{~F}^{-/-}$background. Alternatively, free E2F may not be completely released during the cell cycle and its concentration may remain at a level that is insufficient to trigger an apoptotic response. Results from Farnham and coworkers may provide some support for this possibility (Wells et al. 2000). Using chromatin immunoprecipitation assays to assess which proteins are bound to endogenous genes containing E2F sites at different points during the cell cycle, this group found evidence of E2F-pocket protein complexes still associated with many cell cycle gene promoters during $S$ phase. At first glance, this observation seems contrary to expectations. However, it appears that chromatin remodeling corepressors may be removed progressively from Rb-E2F as cells move through $G_{1}$ into $S$ phase (Zhang et al. 2000), and this loss of corepressor activity seems to prevent active repression by $\mathrm{Rb}$ family members and to allow expression of S-phase genes. If the above model is correct, then free E2F may only accumulate sufficiently to trigger apoptosis when $\mathrm{Rb}$ function is lost, or perhaps when abnormal proliferative conditions in the cell lead to high cyclin E-cdk2 activity sufficient to phosphorylate $\mathrm{Rb}$ on Ser 567, at the A-B pocket interface, leading to a complete release of free E2F.

However, a recently published report from the Dynlacht group has reached different conclusions using similar chromatin immunoprecipitation assays to assess promoter occupancy of some of the same genes by Rb/E2F family members during the cell cycle (Takahashi et al. 2000). In this study the investigators found an E2F4/p130 complex at promoters during $\mathrm{G}_{0}$, which was associated with deacetylation of histones $\mathrm{H} 3$ and $\mathrm{H} 4$ on the pro-

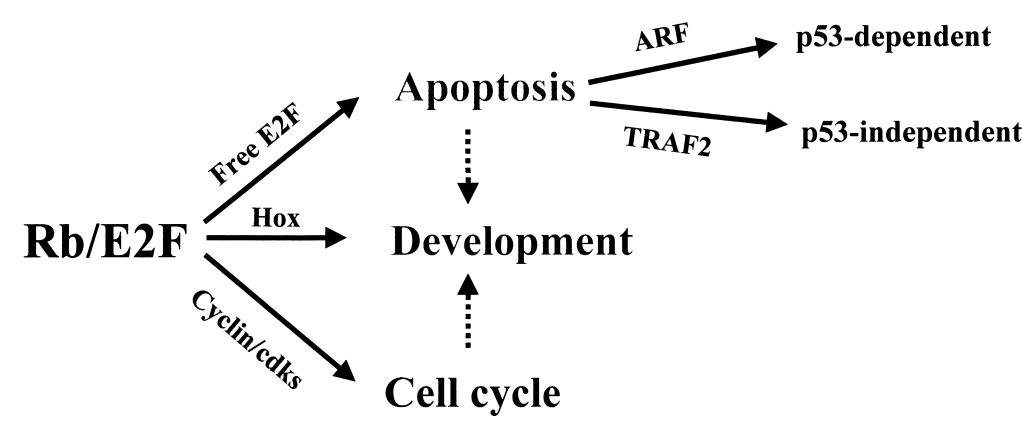

Figure 5. Previous studies have implicated the $\mathrm{Rb} /$ E2F pathway in regulation of the cell cycle and in control of apoptosis. Recent studies in Xenopus now raise the possibility that $\mathrm{Rb} / \mathrm{E} 2 \mathrm{~F}$ plays a direct role in the regulation of Hox genes and development (Suzuki and Hemmati-Brivanlou 2000). Although this will need to be further confirmed, these results raise the possibility that roles for the Rb/E2F pathway may be about to expand. 
moters. By late $G_{1}$, there was a switch to E2F1-3 on most of the promoters, which was associated with an increase in acetylation of histones. E2F binding to the promoters diminished significantly or was absent during $S$ phase. Little or no $\mathrm{Rb}$ was detected in association with any of the genes at any stage of the cell cycle. This result is surprising, particularly given that the investigators detected abundant Rb-E2F complexes forming in $\mathrm{G}_{1}$ and persisting into $S$ phase in their cells by gel-shift assay. Although such a negative result is sometimes difficult to interpret (particularly in such indirect assays), these studies suggest that, although Rb-E2F complexes form in the cells, they do not make their way to the promoters. These results from the Dynlacht group raise the possibility that $\mathrm{Rb}$ may not have a general role in normal cell cycling — for example, it may only regulate the cell cycle in response to $\mathrm{G}_{1}$-checkpoint activation. At first glance, this possibility is somewhat difficult to accept, given the substantial developmental and apoptotic defects seen in mice that lack Rb. However, it is important to point out that the developmental roles of $\mathrm{Rb}$ might not depend on its recruitment to a promoter via E2F, or the $\mathrm{Rb}-\mathrm{E} 2 \mathrm{~F}$ complex may target genes other than those that control the cell cycle that were assayed in these studies (see below). Alternatively, these results in culture, where cells are exposed to very high concentrations of serum growth factors (and thus growth is maximally stimulated), may not entirely replicate cell cycle control in vivo, and under such conditions $\mathrm{Rb}$ (and perhaps p107) function could be limited to a checkpoint-like role. Additional experiments examining other genes, differing conditions (e.g., positive controls activating $G_{1}$ checkpoints and leading to accumulation of hypophosphorylated $\mathrm{Rb}$ ), and more normal cells may be required to further assess this occupancy issue, which is critical for our understanding of the role of $\mathrm{Rb} / \mathrm{E} 2 \mathrm{~F}$ family proteins.

Loss of $\mathrm{Rb}$ can also trigger p53-independent apoptosis (Pan and Griep 1995), but unlike p53-dependent apoptosis, this apoptosis does not require E2F transactivation and can be triggered by expression of the E2F DNA-binding domain alone (Hsieh et al. 1997; Phillips et al. 1997). This suggests that, in this distinct apoptotic pathway, free E2F may serve to displace the Rb-E2F repressor complex from genes. However, it is important to point out that this apoptosis occurs readily in functionally $\mathrm{Rb}^{-}$ cells, so the role of the E2F DNA-binding domain may instead be to displace free E2F from promoters. Although this would seem counterintuitive to the well-accepted idea that free E2F triggers apoptosis, it points out that free E2F is likely to be triggering apoptosis through two distinct pathways. This form of apoptosis is also associated with down-regulation of antiapoptotic proteins such as TRAF2 (Fig. 5; Phillips et al. 1999), but the mechanism of this down-regulation is still unclear. Both of these forms of apoptosis may be operative in vivo, as apoptosis in the central nervous system of $\mathrm{Rb}^{-/-}$mice is p53-dependent, whereas the apoptosis that occurs in the peripheral nervous system is p53-independent (Macleod et al. 1996). Thus an important direction for future re- search is to determine the relative contributions and the molecular targets of these p53-dependent and p53-independent apoptotic pathways in vivo.

\section{Expanding roles for E2F and Rb in development?}

E2F sites are found in the promoters of a number of genes that control the cell cycle and genes, such as ARF, that regulated p53-dependent apoptosis, leading to a widely held belief that the $\mathrm{Rb} / \mathrm{E} 2 \mathrm{~F}$ pathway is restricted to cell cycle control and apoptosis. However, recent results now challenge this paradigm. In a screen for genes that are involved in anterior-posterior axis formation in Xenopus, an $\mathrm{xE} 2 \mathrm{~F}$ gene was identified that is most closely related to E2F3 (Suzuki and Hemmati-Brivanlou 2000). Overexpression of $\mathrm{xE2F}$ led to ectopic expression of ventral and posterior markers and to suppression of the development of dorsoanterior structures. Conversely, when the investigators expressed a dominant-negative construct where the xE2F DNA-binding domain was fused to the engrailed repressor domain, ventral and posterior structures were inhibited. Further, the author showed that ectopic xE2F directly regulated Hox genes to control anterior-posterior axis formation, and it did not appear to function in cell cycle control. In these assays, however, the xE2F DNA-binding domain alone (which should displace endogenous xE2F from Hox genes) had no detectable effect. Thus although $\mathrm{xE2F}$ or $\mathrm{xE} 2 \mathrm{~F}-$-engrailed can regulate Hox genes when overexpressed, these results raise the question as to whether endogenous $\mathrm{xE2F}$ is actually regulating Hox genes during the course of these assays. If this is the case, it would highlight a hitherto unanticipated role for Rb/E2F. Accordingly, these results in Xenopus now raise the question of whether the defects observed in mice in which $\mathrm{Rb} / \mathrm{E} 2 \mathrm{~F}$-pathway genes are mutated are the result solely of aberrant cell cycle control and apoptosis, or if these defects are caused at least in part by deregulation of developmental controls genes (Fig. 5). Furthermore, these results suggest that $\mathrm{E} 2 \mathrm{~F}$ may directly regulate developmental genes through a mechanism that is independent of the cell cycle. Taken together with recent results from the Dynlacht group (Takahashi et al. 2000), which suggest that $\mathrm{Rb}$ is not associated with genes that control the cell cycle in cultured cells, this may eventually force us to readdress an old question in the field as to whether the $\mathrm{Rb}-\mathrm{E} 2 \mathrm{~F}$ pathway is actually critical for control of the normal cell cycle, or if it serves primarily as a checkpoint that becomes activated in response to cellular deregulation.

\section{The Rb-related proteins p107 and p130 and Rb function}

Two other pocket proteins, p107 and p130, are homologous with $\mathrm{Rb}$ within the pocket, and they also bind viral oncoproteins and E2F (Ewen et al. 1991; Hannon et al. 1993). All three pocket proteins can inhibit E2F-responsive promoters (Zamanian and La 1993), recruit HDAC to the pocket (Ferreira et al. 1998), actively repress transcription (Bremner et al. 1995; Starostik et al. 1996), and 
arrest the growth of cells when they are overexpressed (Zhu et al. 1993; Claudio et al. 1994; Starostik et al. 1996). Although this review has focused on $\mathrm{Rb}$, it is important to convey that this protein does not function in isolation, and that there is mounting evidence that the pocket protein family members collaborate functionally. Therefore, we have included a brief discussion of p107 and p130 below, focusing primarily on recent results relating their function to that of $\mathrm{Rb}$.

There are significant differences between the pocket proteins. For example, the spacer region between domains $\mathrm{A}$ and $\mathrm{B}$ in $\mathrm{Rb}$ is not conserved across species or in p107/p130 and has no known function, whereas this region is conserved between p107 and p130 and contains a p21-like sequence through which these proteins bind and inhibit cyclin E- and cyclin A-cdk2 complexes (Ewen et al. 1992; Zhu et al. 1995b; Adams et al. 1996; Lacy and Whyte 1997). This binding has been shown to mediate growth suppression by p107 (Zhu et al. 1995a). Studies examining interactions of the pocket proteins with E2F during cell growth and terminal differentiation have pointed out additional differences between the pocket proteins. In general, $\mathrm{Rb}$ can bind E2F1-4, whereas p107 and p130 bind to E2F4 and E2F5 (Hijmans et al. 1995; Sardet et al. 1995; Nevins 1998). E2F4-p130 is the most abundant complex in quiescent cells, and during differentiation of muscle cells. For example, Rb-E2F complexes are replaced by p130-E2F complexes, which are required to maintain inhibition of DNA synthesis in myotubes (Corbeil et al. 1995; Kiess et al. 1995; Shin et al. 1995). It is unclear why such a switch to p130-E2F is functionally important in quiescent cells, but it is common during development as cells differentiate.

Most experiments in genetically altered animals suggest that the pocket proteins partially overlap in function. Chimeric mice containing Rb-deficient cells do not develop retinal tumors but they are frequent in mice that are also p107-deficient (Robanus-Maandag et al. 1998). Similarly, mice that are heterozygous for $\mathrm{Rb}$ develop normally (Jacks et al. 1992), but the additional homozygous loss of p107 leads to growth retardation and early mortality (Lee et al. 1996). Homozygous Rb deletion leads to embryonic lethality in midgestation (Clarke et al. 1992; Jacks et al. 1992; Lee et al. 1992), whereas the additional homozygous loss of p107 results in lethality two days earlier (Lee et al. 1996). All of these results suggest that p107 and Rb have overlapping but distinct roles in tumor suppression and development. Not only are the phenotypes of mice deficient for Rb, p107, or p130 affected by the presence of the other family members, the phenotypes are also modified dramatically by genetic background (LeCouter et al. 1998), suggesting the presence of strain-specific modifiers of pocket protein activity. Identification and characterization of such modifiers may prove important to ultimately assessing the relative contributions of pocket proteins in vivo and facilitate further understanding of their molecular action.

Primary cells from $p 107^{-/-}$or $p 130^{-/-}$mice showed no deregulation of E2F-responsive genes, whereas cells from $p 107^{-/ /} / p 130^{-/-}$mice showed deregulation of different genes than were found in analogous $\mathrm{Rb}^{-/-}$cells (Hurford et al. 1997). Similarly, in growth-limiting conditions, $\mathrm{Rb}^{-/-}$mouse embryo fibroblasts (MEFs) entered $\mathrm{S}$ phase and E2F target genes were deregulated, suggesting that expression of p107 and p130 are not sufficient substitutes for $\mathrm{Rb}$ in the arrest of $\mathrm{G}_{1}$ and the repression of some E2F genes (Almasan et al. 1995). Arrest of cell growth by p16 depends on $\mathrm{Rb}$, suggesting that the other pocket proteins cannot substitute for $\mathrm{Rb}$ in $\mathrm{p} 16$-mediated growth arrest. In contrast, p16 did not arrest cell growth in $\mathrm{Rb}^{+/+}$ MEFs that lacked p107 and p130, suggesting that transcriptional repression by p107 and p130 may be required in addition to that of $\mathrm{Rb}$ for $\mathrm{p} 16$-mediated growth arrest (N. Dyson and L. Zhu, pers. comm.). Alternatively, p107 and p130 bind to cyclin E-cdk2 and cyclin A-cdk2 (Hannon et al. 1993; Zhu et al. 1995b) and they may be required to titrate cdk2 activity down to a level at which transcriptional repression by $\mathrm{Rb}$ can effectively arrest cells. Mutations in p107/p130 that block repression but leave the p21-like spacer intact, or those that delete the space, leaving the repression domain intact (Starostik et al. 1996) may ultimately prove useful in defining the role of p107/p130 in this situation. In any event, new results point to an intimate relationship between $\mathrm{Rb}$ and the other pocket proteins and indicate that $\mathrm{Rb}$ function depends on p107/p130 (Fig. 6). Additional studies are now warranted to examine the molecular basis of this relationship.

\section{Conclusions}

Although $\mathrm{Rb}$ was the first of the tumor-suppressing genes to be identified, and the Rb/E2F pathway has been studied widely, new findings in the past several years challenge our notions regarding the molecular mechanisms of this pathway and its role in vivo. Although there has been some success in characterizing the molecular basis of $\mathrm{Rb}$ function, the elaborate mechanism of $\mathrm{Rb}$ regulation by cdks, and the linkage of these pathways to extracellular signals, many of the basic issues regarding the role of the $\mathrm{Rb} / \mathrm{E} 2 \mathrm{~F}$ pathway remain unanswered. Some of the fundamental issues are:

1. What is the relative contribution in vivo of inhibition of E2F transcriptional activation by $\mathrm{Rb}$ versus active repression by the $\mathrm{Rb} / \mathrm{E} 2 \mathrm{~F}$ complex mediated by chromatin-remodeling enzymes?

2. How does the cell distinguish between the free E2F that is thought to accumulate as a result of $\mathrm{Rb}$ hyperphosphorylation in a normal cell cycle, and the free $\mathrm{E} 2 \mathrm{~F}$ that triggers apoptosis as a result of loss of $\mathrm{Rb}$ function?

3. What are the mechanisms and relative roles for p53dependent and p53-independent forms of apoptosis, which appear to be triggered through distinct pathways in response to release of free E2F?

4. Do the developmental defects that are observed when $\mathrm{Rb} / \mathrm{E} 2 \mathrm{~F}$ pathway members are mutated result from altered cell cycle control or do they result from direct effects on developmental control genes?

5. What is the role for $\mathrm{Rb}$ in transcriptional activation 


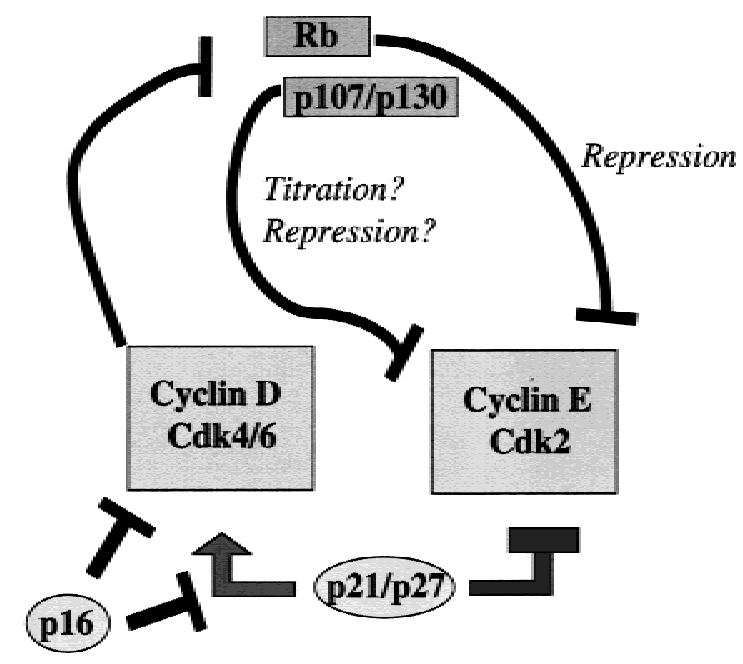

Figure 6. Potential interactions among cdks, cdk inhibitors, and $\mathrm{Rb}$ pocket protein family members. Several different studies have shown that the cdk2 inhibitors p21 and p27 not only inhibit cdk2 but also associate with cyclin D-cdk4/6. However, in contrast to cdk2, this association cdk promotes assembly of an active kinase and titrates the inhibitors away from cdk2, thereby increasing cdk2 activity in the cell. p16 binds to cdk4/6, inhibiting its activity, and displaces p21 and p27, freeing them to inhibit cdk2. Both the accumulation of hypophosphorylated $\mathrm{Rb}$, which results from the p16-mediated inhibition of cdk4/6, and the inhibition of cdk2 activity by $\mathrm{p} 21 / \mathrm{p} 27$ (displaced from cyclin D-cdk4/6 by p16) appear to be required for complete inhibition of cdk2 and growth suppression. (For detailed review of this pathway, see Sherr and Roberts 1999). New studies from both the Dyson and Zhu groups indicate that p107/p130 is also required for this growth suppression. p107 and p130 can bind to cdk2 (via a p21-like sequence in the spacer region of the pocket), blocking its activity. Thus, these proteins may serve a function similar to p21/p27-titration of active cdk2. However, like Rb, they are capable of repressing transcription. Thus it is also possible that $\mathrm{p} 107 / \mathrm{p} 130$ contributes to the transcriptional repression displayed by $\mathrm{Rb}$. Nevertheless, such recent results link the three pocket proteins together functionally.

(e.g., in transcriptional activation by MyoD during muscle differentiation or in response to glucocorticoids)?

6. $\mathrm{Rb}$ is frequently mutated in tumors, whereas p107 and p130 do not yet seem to be, highlighting a unique function for $\mathrm{Rb}$. These results emphasize the fact that we still know little about the functions of p107 and p130 or about the intricate relationship between the three pocket proteins that is only now becoming apparent.

Resolving these and other issues regarding the $\mathrm{Rb} / \mathrm{E} 2 \mathrm{~F}$ pathway in the upcoming years should eventually allow us to assess its complex and expanding roles in vivo.

\section{Acknowledgments}

We thank the numerous investigators that have shared their results with us before their publication. We are also indebted to the reviewers for many helpful and constructive comments on the manuscript.

\section{References}

Adams, P.D., Li, X., Sellers, W.R., Baker, K.B., Leng, X., Harper, J.W., Taya, Y., and Kaelin, Jr., W.G. 1999. Retinoblastoma protein contains a C-terminal motif that targets it for phosphorylation by cyclin-Cdk complexes. Mol. Cell. Biol. 19: $1068-1080$.

Adams, P.D., Sellers, W.R., Sharma, S.K., Wu, A.D., Nalin, C.M., and Kaelin, Jr., W.G. 1996. Identification of a cyclinCdk2 recognition motif present in substrates and p21like cyclin-dependent kinase inhibitors. Mol. Cell. Biol. 16: 6623-6633.

Adnane, J., Shao, Z., and Robbins, P.D. 1995. The retinoblastoma susceptibility gene product represses transcription when directly bound to the promoter. J. Biol. Chem. 270: 88378843.

Alland, L., Muhle, R., Hou, Jr., H., Potes, J., Chin, L., SchreiberAgus, N., and DePinho, R.A. 1997. Role for N-CoR and histone deacetylase in Sin3-mediated transcriptional repression. Nature 387: 49-55.

Almasan, A., Yin, Y., Kelly, R.E., Lee, E.Y., Bradley, A., Li, W., Bertino, J.R., and Wahl, G.M. 1995. Deficiency of retinoblastoma protein leads to inappropriate S-phase entry, activation of E2F-responsive genes, and apoptosis. Proc. Natl. Acad. Sci. 92: 5436-5440.

Asano, M. and Wharton, R.P. 1999. E2f mediates developmental and cell cycle regulation of ORC1 in Drosophila. EMBO $\mathrm{J}$. 18: 2435-2448.

Bartek, J., Bartkova, J., and Lukas. J. 1997. The retinoblastoma protein pathway in cell cycle control and cancer. Exp. Cell. Res. 237: 1-6.

Bates, S., Phillips, A.C., Clark, P.A., Stott, F., Peters, G., Ludwig, R.L., and Vousden, K.H. 1998. p14ARF links the tumour suppressors RB and p53. Nature 395: 124-125.

Blake, M.C. and Azizkhan, J.C. 1989. Transcription factor E2F is required for efficient expression of the hamster dihydrofolate reductase gene in vitro and in vivo. Mol. Cell. Biol. 9: 49945002.

Bookstein, R., Rio, P., Madreperla, S.A., Hong, F., Allred, C., Grizzle, W.E., and Lee, W.H. 1990. Promoter deletion and loss of retinoblastoma gene expression in human prostate carcinoma. Proc. Natl. Acad. Sci. 87: 7762-7766.

Brandeis, M. and Hunt, T. 1996. The proteolysis of mitotic cyclins in mammalian cells persists from the end of mitosis until the onset of S phase. EMBO J. 15: 5280-5289.

Brehm, A., Miska, E.A., McCance, D.J., Reid, J.L., Bannister, A.J., and Kouzarides, T. 1998. Retinoblastoma protein recruits histone deacetylase to repress transcription. Nature 391: 597-601.

Bremner, R., Cohen, B.L., Sopta, M., Hamel, P.A., Ingles, C.J., Gallie, B.L., and Phillips, R.A. 1995. Direct transcriptional repression by $\mathrm{pRB}$ and its reversal by specific cyclins. Mol. Cell. Biol. 15: 3256-3265.

Chellappan, S.P., Hiebert, S., Mudryj, M., Horowitz, J.M., and Nevins, J.R. 1991. The E2F transcription factor is a cellular target for the RB protein. Cell 65: 1053-1061.

Chen, P.L., Scully, P., Shew, J.Y., Wang, J.Y., and Lee, W.H. 1989. Phosphorylation of the retinoblastoma gene product is modulated during the cell cycle and cellular differentiation. Cell 58: 1193-1198.

Chen, T.T. and Wang, J.Y. 2000. Establishment of irreversible growth arrest in myogenic differentiation requires the $\mathrm{RB}$ 
LXCXE-binding function. Mol. Cell Biol. 20: 5571-5580.

Chow, K.N. and Dean, D.C. 1996. Domains A and B in the Rb pocket interact to form a transcriptional repressor motif. Mol. Cell. Biol. 16: 4862-4868.

Chow, K.N., Starostik, P., and Dean, D.C. 1996. The Rb family contains a conserved cyclin-dependent-kinase-regulated transcriptional repressor motif. Mol. Cell. Biol. 16: 71737181.

Clarke, A.R., Maandag, E.R., van Roon, M., van der Lugt, N.M., van der Valk, M., Hooper, M.L., Berns, A., and te Riele, H. 1992. Requirement for a functional $R b-1$ gene in murine development. Nature 359: 328-330.

Claudio, P.P., Howard, C.M., Baldi, A., De Luca, A., Fu, Y., Condorelli, G., Sun, Y., Colburn, N., Calabretta, B., and Giordano, A. 1994. p130/pRb2 has growth suppressive properties similar to yet distinctive from those of retinoblastoma family members pRb and p107. Cancer Res. 54: 5556-5560.

Corbeil, H.B., Whyte, P., and Branton, P.E. 1995. Characterization of transcription factor E2F complexes during muscle and neuronal differentiation. Oncogene 11: 909-920.

Cosma, M.P., Tanaka, T., and Nasmyth, K. 1999. Ordered recruitment of transcription and chromatin remodeling factors to a cell cycle- and developmentally regulated promoter. Cell 97: 299-311.

Dahiya, A., Gavin, M.R., Luo, R.X., and Dean, D.C. 2000. Role of the LXCXE binding site in Rb function. Mol. Cell. Biol. 20: 6799-6805.

Dalton, S. 1992. Cell cycle regulation of the human cdc2 gene. EMBO I. 11: 1797-1804.

de la Luna, S., Allen, K.E., Mason, S.L., and La Thangue, N.B. 1999. Integration of a growth-suppressing BTB/POZ domain protein with the DP component of the E2F transcription factor. $E M B O J$. 18: 212-228.

DeCaprio, J.A., Ludlow, J.W., Figge, J., Shew, J.Y., Huang, C.M., Lee, W.H., Marsilio, E., Paucha, E., and Livingston, D.M. 1988. SV40 large tumor antigen forms a specific complex with the product of the retinoblastoma susceptibility gene. Cell 54: 275-283.

DeGregori, J., Leone, G., Miron, A., Jakoi, L., and Nevins, J.R. 1997. Distinct roles for e2f proteins in cell growth control and apoptosis. Proc. Natl. Acad. Sci. 94: 7245-7250.

Dunaief, J.L., Strober, B.E., Guha, S., Khavari, P.A., Alin, K., Luban, J., Begemann, M., Crabtree, G.R., and Goff, S.P. 1994. The retinoblastoma protein and BRG1 form a complex and cooperate to induce cell cycle arrest. Cell 79: 119-130.

Durfee, T., Mancini, M.A., Jones, D., Elledge, S.J., and Lee, W.H. 1994. The amino-terminal region of the retinoblastoma gene product binds a novel nuclear matrix protein that co-localizes to centers for RNA processing. J. Cell. Biol. 127: 609622.

Duronio, R.J., O’Farrell, P.H., Xie, J.E., Brook, A., and Dyson, N. 1995. The transcription factor E2F is required for $S$ phase during Drosophila embryogenesis. Genes \& Dev. 9: 14451455.

Dynlacht, B.D., Brook, A., Dembski, M., Yenush, L., and Dyson, N. 1994. DNA-binding and trans-activation properties of Drosophila E2F and DP proteins. Proc. Natl. Acad. Sci. 91: 6359-6363.

Dyson, N. 1998. The regulation of E2F by pRB-family proteins. Genes \& Dev. 12: 2245-2262.

Dyson, N., Howley, P.M., Munger, K., and Harlow, E. 1989. The human papilloma virus-16 E7 oncoprotein is able to bind to the retinoblastoma gene product. Science 243: 934-937.

Eng, C., Li, F.P., Abramson, D.H., Ellsworth, R.M., Wong, F.L., Goldman, M.B., Seddon, J., Tarbell, N., and Boice, J.J. 1993. Mortality from second tumors among long-term survivors of retinoblastoma. J. Natl. Cancer Inst. 85: 1121-1128.

Ewen, M.E., Faha, B., Harlow, E., and Livingston, D.M. 1992. Interaction of p107 with cyclin A independent of complex formation with viral oncoproteins. Science 255: 85-87.

Ewen, M.E., Xing, Y.G., Lawrence, J.B., and Livingston, D.M. 1991. Molecular cloning, chromosomal mapping, and expression of the cDNA for $\mathrm{p} 107$, a retinoblastoma gene product-related protein. Cell 66: 1155-1164.

Ezhevsky, S.A., Nagahara, H., Vocero, A.A., Gius, D.R., Wei, M.C., and Dowdy, S.F. 1997. Hypo-phosphorylation of the retinoblastoma protein $(\mathrm{pRb})$ by cyclin $\mathrm{D}: \mathrm{Cdk} 4 / 6$ complexes results in active pRb. Proc. Nat1. Acad. Sci. 94: 1069910704.

Felsenfeld, G. 1992. Chromatin as an essential part of the transcriptional mechanism. Nature 355: 219-224.

Ferreira, R., Magnaghi-Jaulin, L., Robin, P., Harel-Bellan, A., and Trouche, D. 1998. The three members of the pocket proteins family share the ability to repress E2F activity through recruitment of a histone deacetylase. Proc. Natl. Acad. Sci. 95: 10493-10498.

Flemington, E.K., Speck, S.H., and Kaelin, W.G., Jr. 1993. E2F1-mediated transactivation is inhibited by complex formation with the retinoblastoma susceptibility gene product. Proc. Natl. Acad. Sci. 90: 6914-6918.

Friend, S.H., Bernards, R., Rogelj, S., Weinberg, R.A., Rapaport, J.M., Albert, D.M., and Dryja, T.P. 1986. A human DNA segment with properties of the gene that predisposes to retinoblastoma and osteosarcoma. Nature 323: 643-646.

Fung, Y.K., Murphree, A.L., T'Ang, A., Qian, J., Hinrichs, S.H., and Benedict, W.F. 1987. Structural evidence for the authenticity of the human retinoblastoma gene. Science 236: 16571661.

Geng, Y., Whoriskey, W., Park, M.Y., Bronson, R.T., Medema, R.H., Li, T., Weinberg, R.A., and Sicinski, P. 1999. Rescue of cyclin D1 deficiency by knockin of cyclin E. Cell 97: 767777.

Grunstein, M. 1997. Histone acetylation in chromatin structure and transcription. Nature 389: 349-352.

Gu, W., Schneider, J.W., Condorelli, G., Kaushal, S., Mahdavi, V., and Nadal-Ginard, B. 1993. Interaction of myogenic factors and the retinoblastoma protein mediates muscle cell commitment and differentiation. Cell 72: 309-324.

Hannon, G.J., Demetrick, D., and Beach, D. 1993. Isolation of the Rb-related p130 through its interaction with CDK2 and cyclins. Genes \& Dev. 7: 2378-2391.

Harbour, J.W. 1998. Overview of $R B$ gene mutations in patients with retinoblastoma. Implications for clinical genetic screening. Ophthalmology 105: 1442-1447.

Harbour, J.W., Lai, S.L., Whang-Peng, J., Gazdar, A.F., Minna, J.D., and Kaye, F.J. 1988. Abnormalities in structure and expression of the human retinoblastoma gene in SCLC. Science 241: 353-357.

Harbour, J.W., Luo, R.X., Dei Sante, A., Postigo, A.A., and Dean, D.C. 1999. Cdk phosphorylation triggers sequential intramolecular interactions that progressively block $\mathrm{Rb}$ functions as cells move through $\mathrm{G}_{1}$. Cell 98: 859-869.

Hassig, C.A., Fleischer, T.C., Billin, A.N., Schreiber, S.L., and Ayer, D.E. 1997. Histone deacetylase activity is required for full transcriptional repression by mSin3A. Cell 89: 341-347.

Hassig, C.A. and Schreiber, S.L. 1997. Nuclear histone acetylases and deacetylases and transcriptional regulation: HATs off to HDACs. Curr. Opin. Chem. Biol. 1: 300-308.

Haupt, Y., Maya, R., Kazaz, A., and Oren, M. 1997. Mdm2 promotes the rapid degradation of p53. Nature 387: 296-299.

He, S., Cook, B.L., Deverman, B.E., Weihe, U., Zhang, F., Prachand, V., Zheng, J., and Weintraub, S.J. 2000. E2F is required 
to prevent inappropriate S-phase entry of mammalian cells. Mol. Cell. Biol. 20: 363-371.

Heinzel, T., Lavinsky, R.M., Mullen, T.M., Soderstrom, M., Laherty, C.D., Torchia, J., Yang, W.M., Brard, G., Ngo, S.D., Davie, J.R., et al. 1997. A complex containing N-CoR, mSin3 and histone deacetylase mediates transcriptional repression. Nature 387: 43-48.

Helin, K., Harlow, E., and Fattaey, A. 1993. Inhibition of E2F-1 transactivation by direct binding of the retinoblastoma protein. Mol. Cell. Biol. 13: 6501-6508.

Hijmans, E.M., Voorhoeve, P.M., Beijersbergen, R.L., van'tVeer, L.J., and Bernards, R. 1995. E2F-5, a new E2F family member that interacts with p130 in vivo. Mol. Cell. Biol. 15: 3082 3089.

Hinds, P.W., Mittnacht, S., Dulic, V., Arnold, A., Reed, S.I., and Weinberg, R.A. 1992. Regulation of retinoblastoma protein functions by ectopic expression of human cyclins. Cell 70: $993-1006$.

Holstege, F.C., Jennings, E.G., Wyrick, J.J., Lee, T.I., Hengartner, C.J., Green, M.R., Golub, T.R., Lander, E.S., and Young, R.A. 1998. Dissecting the regulatory circuitry of a eukaryotic genome. Cell 95: 717-728.

Horowitz, J.M., Park, S.H., Bogenmann, E., Cheng, J.C., Yandell, D.W., Kaye, F.J., Minna, J.D., Dryja, T.P., and Weinberg, R.A. 1990. Frequent inactivation of the retinoblastoma anti-oncogene is restricted to a subset of human tumor cells. Proc. Natl. Acad. Sci. 87: 2775-2779.

Hsiao, K.M., McMahon, S.L., and Farhham, P.J. 1994. Multiple DNA elements are required for the growth regulation of the mouse E2F-1 promoter. Genes \& Dev. 13: 1526-1537.

Hsieh, J.K., Chan, F.S., O'Connor, D.J., Mittnacht, S., Zhong, S., and $\mathrm{Lu}, \mathrm{X} .1999$. RB regulates the stability and the apoptotic function of p53 via MDM2. Mol. Cell 3: 181-193.

Hsieh, J.K., Fredersdorf, S., Kouzarides, T., Martin, K., and Lu, X. 1997. E2F1-induced apoptosis requires DNA binding but not transactivation and is inhibited by the retinoblastoma protein through direct interaction. Genes \& Dev. 11: 18401852.

Huang, H.J., Yee, J.K., Shew, J.Y., Chen, P.L., Bookstein, R.,. Friedmann, T, Lee, E.Y., and Lee, W.H. 1988. Suppression of the neoplastic phenotype by replacement of the $R B$ gene in human cancer cells. Science 242: 1563-1566.

Huang, S., Shin, E., Sheppard, K.A., Chokroverty, L., Shan, B., Qian, Y.W., Lee, E.Y., and Yee, A.S. 1992. The retinoblastoma protein region required for interaction with the $\mathrm{E} 2 \mathrm{~F}$ transcription factor includes the T/E1A binding and carboxyterminal sequences. DNA Cell. Biol. 11: 539-548.

Humbert, P.O., Raluca, V., Trimarchi, J.M., Rogers, C., Dandapani, S., and Lees, J.A. 2000. E2f3 is critical for normal cellular proliferation. Genes \& Dev. 14: 690-703.

Hurford, R.J., Cobrinik, D., Lee, M.H., and Dyson, N. 1997.pRB and $\mathrm{p} 107 / \mathrm{p} 130$ are required for the regulated expression of different sets of E2F responsive genes. Genes \& Dev. 11: $1447-1463$.

Jacks, T., Fazeli, A., Schmitt, E.M., Bronson, R.T., Goodell, M.A., and Weinberg, R.A. 1992. Effects of an Rb mutation in the mouse. Nature 359: 295-300.

Johnson, D.G., Schwarz, J.K., Cress, W.D., and Nevins, J.R. 1993. Expression of transcription factor E2F1 induces quiescent cells to enter S phase. Nature 365: 349-352.

Johnson, D.G., Ohtani, K., and Nevins, J.R. 1994. Autoregulatory control of E2F1 expression in response to positive and negative regulators of cell cycle progression. Genes \& Dev. 13: 1514-1525.

Kiess, M., Gill, R.M., and Hamel, P.A. 1995. Expression and activity of the retinoblastoma protein (pRB)-family proteins, p107 and p130, during L6 myoblast differentiation. Cell Growth Differ. 6: 1287-1298.

Kim, H.Y. and Cho, Y. 1997. Structural similarity between the pocket region of retinoblastoma tumour suppressor and the cyclin-box. Nat. Struct. Biol. 4: 390-395.

Kingston, R.E. and Narlikar, G.J. 1999. ATP-dependent remodeling and acetylation as regulators of chromatin fluidity. Genes \& Dev. 13: 2339-2352.

Knudsen, E.S., Buckmaster, C., Chen, T.T., Feramisco, J.R., and Wang, J.Y. 1998. Inhibition of DNA synthesis by RB: Effects on G1/S transition and S-phase progression. Genes \& Dev. 12: 2278-2292.

Knudsen, E.S. and Wang, J.Y. 1996. Differential regulation of retinoblastoma protein function by specific Cdk phosphorylation sites. J. Biol. Chem. 271: 8313-8320

.1997. Dual mechanisms for the inhibition of E2F binding to RB by cyclin-dependent kinase-mediated RB phosphorylation. Mol. Cell. Biol. 17: 5771-5783.

Kornberg, R.D. and Lorch, Y. 1999. Twenty-five years of the nucleosome, fundamental particle of the eukaryote chromosome. Cell 98: 285-294.

Krude, T., Jackson, M., Pines, J., and Laskey, R.A. 1997. Cyclin/ Cdk-dependent initiation of DNA replication in a human cell-free system. Cell 88: 109-119.

Kubbutat, M.H., Jones, S.N., and Vousden, K.H. 1997. Regulation of p53 stability by Mdm2. Nature 387: 299-303.

Lacy, S. and Whyte, P. 1997. Identification of a p130 domain mediating interactions with cyclin $\mathrm{A} / \mathrm{cdk} 2$ and cyclin $\mathrm{E} / \mathrm{cdk}$ 2 complexes. Oncogene 14: 2395-4206.

Laherty, C.D., Yang, W.M., Sun, J.M., Davie, J.R., Seto, E., and Eisenman, R.N. 1997. Histone deacetylases associated with the $\mathrm{mSin} 3$ corepressor mediate mad transcriptional repression. Cell 89: 349-356.

Lai, A., Lee, J.M., Yang, W.M., DeCaprio, J.A., Kaelin, Jr., W.G., Seto, E., and Branton, P.E. 1999a. RBP1 recruits both histone deacetylase-dependent and -independent repression activities to retinoblastoma family proteins. Mol. Cell. Biol. 19: 6632-6641.

Lai, A., Marcellus, R.C., Corbeil, H.B., and Branton, P.E.. 1999b. $\mathrm{RBP1}$ induces growth arrest by repression of E2F-dependent transcription. Oncogene 18: 2091-2100.

LeCouter, J.E., Kablar, B., Hardy, W.R., Ying, C., Megeney, L.A., May, L.L., and Rudnicki, M.A. 1998. Strain-dependent myeloid hyperplasia, growth deficiency, and accelerated cell cycle in mice lacking the Rb-related p107 gene. Mol. Cell. Biol. 18: 7455-7465.

Lee, W.H., Bookstein, R., Hong, F., Young, L.J., Shew, J.Y., and Lee, E.Y. 1987. Human retinoblastoma susceptibility gene: cloning, identification, and sequence. Science 235: 13941399.

Lee, E.Y., Chang, C.Y., Hu, N., Wang, Y.C., Lai, C.C., Herrup, K., Lee, W.H, and Bradley, A. 1992. Mice deficient for Rb are nonviable and show defects in neurogenesis and haematopoiesis. Nature 359: 288-294.

Lee, J.O., Russo, A.A., and Pavletich, N.P. 1998. Structure of the retinoblastoma tumour-suppressor pocket domain bound to a peptide from HPV E7. Nature 391: 859-865.

Lee, E.Y., To, H., Shew, J.Y., Bookstein, R., Scully, P., and Lee, W.H. 1988. Inactivation of the retinoblastoma susceptibility gene in human breast cancers. Science 241: 218-221.

Lee, M.H., Williams, B.O., Mulligan, G., Mukai, S., Bronson, R.T., Dyson, N., Harlow, E., and Jacks, T. 1996. Targeted disruption of p107: Functional overlap between p107 and Rb. Genes \& Dev. 10: 1621-1632.

Leng, X., Connell, C.L., Goodrich, D., and Harper, J.W. 1997. S-Phase entry upon ectopic expression of $G_{1}$ cyclin-depen- 
dent kinases in the absence of retinoblastoma protein phosphorylation. Curr. Biol. 7: 709-712.

Lipinski, M.M., and Jacks, T. 1999. The retinoblastoma gene family in differentiation and development. Oncogene 18: 7873-7882.

Lorch, Y., Zhang, M., and Kornberg, R.D. 1999. Histone octamer transfer by a chromatin-remodeling complex. Cell 96: 389392.

Loughran, O., and La Thangue, N.B. 2000. Apoptotic and growth-promoting activity of E2F modulated by MDM2. Mol. Cell. Biol. 20: 186-197.

Lu, X. and Horvitz, H.R. 1998. lin-35 and lin-53, two genes that antagonize a C. elegans Ras pathway, encode proteins similar to $\mathrm{Rb}$ and its binding protein RbAp48. Cell 95: 981-991.

Ludlow, J.W., DeCaprio, J.A., Huang, C.M., Lee, W.H., Paucha, E., and Livingston, D.M. 1989. SV40 large T antigen binds preferentially to an underphosphorylated member of the retinoblastoma susceptibility gene product family. Cell 56: $57-$ 65.

Lukas, J., Herzinger, T., Hansen, K., Moroni, M.C., Resnitzky, D., Helin, K., Reed, S.I., and Bartek, J. 1997. Cyclin E-induced S phase without activation of the $\mathrm{pRb} / \mathrm{E} 2 \mathrm{~F}$ pathway. Genes \& Dev. 11: 1479-1492.

Lukas, C., Sorensen, C.S., Kramer, E., Santoni-Rugiu, E., Lindeneg, C., Peters, J.M., Bartek, J., and Lukas, J. 1999. Accumulation of cyclin B1 requires E2F and cyclin-A-dependent rearrangement of the anaphase-promoting complex. Nature 401: $815-818$.

Lundberg, A.S. and Weinberg, R.A. 1998. Functional inactivation of the retinoblastoma protein requires sequential modification by at least two distinct cyclin-Cdk complexes. Mol. Cell. Biol. 18: 753-761.

Luo, R.X., Postigo, A.A., and Dean, D.C. 1998. Rb interacts with histone deacetylase to repress transcription. Cell 92: 463 473.

Macleod, K.F., Hu, Y., and Jacks, T. 1996. Loss of Rb activates both p53-dependent and independent cell death pathways in the developing mouse nervous system. EMBO J. 15: 61786188.

Magnaghi, J.L., Groisman, R., Naguibneva, I., Robin, P., Lorain, S., Le, V.J., Troalen, F., Trouche, D., and Harel, B.A. 1998. Retinoblastoma protein represses transcription by recruiting a histone deacetylase. Nature 391: 601-605.

Martinez-Balbas, M.A., Bauer, U.M., Nielsen, S.J., Brehm, A., and Kouzarides, T. 2000. Regulation of E2F1 activity by acetylation. EMBO J. 19: 662-671.

Meloni, A.R., Smith, E.J., and Nevins, J.R. 1999. A mechanism for $\mathrm{Rb} / \mathrm{p} 130$-mediated transcription repression involving recruitment of the CtBP corepressor. Proc. Natl. Acad. Sci. 96: 9574-9579.

Moll, A.C., Imhof, S.M., Bouter, L.M., and Tan, K.E. 1997. Second primary tumors in patients with retinoblastoma. A review of the literature. Ophthalmic Genet. 18: 27-34.

Morgenbesser, S.D., Williams, B.O., Jacks, T., and Depinho, R.A. 1994. p53-dependent apoptosis produced by Rb-deficiency in the developing mouse lens. Nature 371: 72-74.

Neuman, E., Flemington, E.K., Sellers, W.R., and Kaelin, Jr., W.G. 1995. Transcription of the E2F-1 gene is rendered cell cycle dependent by E2F DNA-binding sites within its promoter.Mol. Cell. Biol. 15: 4660.

Nevins, J.R. 1998. Toward an understanding of the functional complexity of the E2F and retinoblastoma families. Cell Growth Differ. 9: 585-593.

Nibu, Y., Zhang, H., and Levine, M. 1998. Interaction of shortrange repressors with Drosophila CtBP in the embryo. Science 280: 101-104.
Nicolas, E., Morales, V., Magnaghi-Jaulin, L., Harel-Bellan, A., Richard-Foy, H., and Trouche, D. 2000. RbAp48 belongs to the histone deacetylase complex that associates with the retinoblastoma Protein. J. Biol. Chem. 275: 9797-9804.

Ohtani, K. and Nevins, J.R. 1994. Functional properties of a Drosophila homolog of the E2F1 gene. Mol. Cell. Biol. 14: 1603-1612.

Ohtani, K., DeGregori, J., and Nevins, J.R. 1995. Regulation of the cyclin $E$ gene by transcription factor E2F1. Proc. Nat1. Acad. Sci. 92: 12146-12150.

Ohtani, K., DeGregori, J., Leone, G., Herendeen, D.R., Kelly, T.J., and Nevins, J.R. 1996. Expression of the HsOrc1 gene, a human $O R C 1$ homolog, is regulated by cell proliferation via the E2F transcription factor. Mol. Cell. Biol. 16: 6977-6984.

Pan, H. and Griep, A.E. 1995. Temporally distinct patterns of p53-dependent and p53-independent apoptosis during mouse lens development. Genes \& Dev. 9: 2157-2169.

Pan, H., Yin, C., Dyson, N.J., Harlow, E., Yamasaki, L., and Van Dyke, T. 1998. Key roles for E2F1 in signaling p53-dependent apoptosis and in cell division within developing tumors. Mol. Cell 2: 283-292.

Phelan, M.L., Sif, S., Narlikar, G.J., and Kingston, R.E. 1999. Reconstitution of a core chromatin remodeling complex from SWI/SNF subunits. Mol. Cell 3: 247-253.

Phillips, A.C., Bates, S., Ryan, K.M., Helin, K., and Vousden, K.H. 1997. Induction of DNA synthesis and apoptosis are separable functions of E2F-1. Genes \& Dev. 11: 1853-1863.

Phillips, A.C., Ernst, M.K., Bates, S., Rice, N.R., and Vousden, K.H. 1999. E2F-1 potentiates cell death by blocking antiapoptotic signaling pathways. Mol. Cell 4: 771-781.

Pomerantz, J., Schreiber, A.N., Liegeois, N.J., Silverman, A., Alland, L., Chin, L., Potes, J., Chen, K., Orlow, I., Lee, H.W., et al. 1998. The Ink4a tumor suppressor gene product, p19Arf, interacts with $\mathrm{Mdm} 2$ and neutralizes Mdm2's inhibition of p53. Cell 92: 713-723.

Qin, X.Q., Chittenden, T., Livingston, D.M., and Kaelin, Jr., W.G. 1992. Identification of a growth suppression domain within the retinoblastoma gene product. Genes \& Dev. 6: 953-964.

Qin, X.Q., Livingston, D.M., Ewen, M., Sellers, W.R., Arany, Z., and Kaelin, Jr., W.G. 1995. The transcription factor E2F-1 is a downstream target of RB action. Mol. Cell. Biol. 15: 742755.

Riley, D.J., Liu, C.Y., and Lee, W.H. 1997. Mutations of Nterminal regions render the retinoblastoma protein insufficient for functions in development and tumor suppression. Mol. Cell. Biol. 17: 7342-7352.

Robanus-Maandag, E., Dekker, M., van der Valk, M., Carrozza, M.L., Jeanny, J.C., Dannenberg, J.H., Berns, A., and te Riele, H. 1998. p107 is a suppressor of retinoblastoma development in pRb-deficient mice. Genes \& Dev. 12: 1599-1609.

Ross, J.F., Liu, X., and Dynlacht, B.D. 1999. Mechanism of transcriptional repression of E2F by the retinoblastoma tumor suppressor protein. Mol. Cell 3: 195-205.

Royzman, I., Austin, R.J., Bosco, G., Bell, S.P., and Orr-Weaver, T.L. 1999. ORC localization in Drosophila follicle cells and the effects of mutations in $d E 2 F$ and $d D P$. Genes \& Dev. 13: $827-840$.

Sardet, C., Vidal, M., Cobrinik, D., Geng, Y., Onufryk, C., Chen, A., and Weinberg, R.A. 1995. E2F-4 and E2F-5, two members of the E2F family, are expressed in the early phases of the cell cycle. Proc. Natl. Acad. Sci. 92: 2403-2407.

Schaeper, U., Subramanian, T., Lim, L., Boyd, J.M., and Chinnadurai, G. 1998. Interaction between a cellular protein that binds to the C-terminal region of adenovirus E1A (CtBP) and a novel cellular protein is disrupted by E1A through a con- 
served PLDLS motif. J. Biol. Chem. 273: 8549-8552.

Schnitzler, G., Sif, S., and Kingston, R.E. 1998. Human SWI/SNF interconverts a nucleosome between its base state and a stable remodeled state. Cell 94: 17-27.

Sellers, W.R., Novitch, B.G., Miyake, S., Heith, A., Otterson, G.A., Kaye, F.J., Lassar, A.B., and Kaelin, Jr., W.G. 1998. Stable binding to E2F is not required for the retinoblastoma protein to activate transcription, promote differentiation, and suppress tumor cell growth. Genes \& Dev. 12: 95-106.

Sellers, W.R., Rodgers, J.W., and Kaelin, Jr., W.G. 1995. A potent transrepression domain in the retinoblastoma protein induces a cell cycle arrest when bound to E2F sites. Proc. Natl. Acad. Sci. 92: 11544-11548.

Shanahan, F., Seghezzi, W., Parry, D., Mahony, D., and Lees, E. 1999. Cyclin E associates with BAF155 and BRG1, components of the mammalian SWI-SNF complex, and alters the ability of BRG1 to induce growth arrest. Mol. Cell. Biol. 19: 1460-1469.

Sherr, C.J. 1996. Cancer cell cycles. Science 274: 1672-1677.

Sherr, C.J. and Roberts, J.M. 1999. CDK inhibitors: positive and negative regulators of $\mathrm{G}_{1}$-phase progression. Genes \& Dev. 13: $1501-1512$.

Shin, E.K., Shin, A., Paulding, C., Schaffhausen, B., and Yee, A.S. 1995. Multiple change in E2F function and regulation occur upon muscle differentiation. Mol. Cell. Biol. 15: 2252-2262.

Sif, S., Stukenberg, P.T., Kirschner, M.W., and Kingston, R.E. 1998. Mitotic inactivation of a human SWI/SNF chromatin remodeling complex. Genes \& Dev. 12: 2842-2851.

Singh, P., Coe, J., and Hong, W. 1995. A role for retinoblastoma protein in potentiating transcriptional activation by the glucocorticoid receptor. Nature 374: 562-565.

Sorensen, T.S., Girling, R., Lee, C.W., Gannon, J., Bandara, L.R., and La Thangue, N.B. 1996. Functional interaction between DP-1 and p53. Mol. Cell. Biol. 16: 5888-5895.

Staehling-Hampton, K., Ciampa, P.J., Brook, A., and Dyson, N. 1999. A genetic screen for modifiers of E2F in Drosophila melanogaster. Genetics 153: 275-287.

Starostik, P., Chow, K.N., and Dean, D.C. 1996. Transcriptional repression and growth suppression by the p107 pocket protein. Mol. Cell. Biol. 16: 3606-3614.

Sterner, J.M., Dew, K.S., Musahl, C., Kornbluth, S., and Horowitz, J.M. 1998. Negative regulation of DNA replication by the retinoblastoma protein is mediated by its association with Mcm7. Mol. Cell. Biol. 18: 2748-2757.

Sterner, J.M., Murata, Y., Kim, H.G., Kennett, S.B., Templeton, D.J., and Horowitz, J.M. 1995. Detection of a novel cell cycle-regulated kinase activity that associates with the amino terminus of the retinoblastoma protein in $G_{2} / M$ phases. J. Biol. Chem. 270: 9281-9288.

Strobeck, M.W., Knudsen, K.E., Fribourg, A.F. DiCristofaro, M.F., Weissman, B.E., Imbalzano, A.N., and Knudsen, E.S. 2000. BRG-1 is required for RB-mediated cell cycle arrest. Proc. Natl. Acad. Sci. 97: 7748-7753.

Suzuki, A. and Hemmati-Brivanlou, A. 2000. Xenopus embryonic E2F is required for the formation of ventral and posterior cell fates during early embryogenesis. Mol. Cell 5: $217-$ 229.

Symonds, H., Krall, L., Remington, L., Saenz-Robles, M., Lowe, S., Jacks, T., and Van Dyke, T. 1994. p53-dependent apoptosis suppresses tumor growth and progression in vivo. Cell 78: 703-711.

T'Ang, A., Varley, J.M., Chakraborty, S., Murphree, A.L., and Fung, Y.K. 1988. Structural rearrangement of the retinoblastoma gene in human breast carcinoma. Science 242: 263 266.

Takahashi, Y., Rayman, J.B., and Dynlacht, B.D. 2000. Analysis of promoter binding by the $\mathrm{E} 2 \mathrm{~F}$ and $\mathrm{Rb}$ families in vivo: distinct E2F proteins mediate activation and repression. Genes \& Dev. 14: 804-816.

Templeton, D.J., Park, S.H., Lanier, L., and Weinberg, R.A. 1991. Nonfunctional mutants of the retinoblastoma protein are characterized by defects in phosphorylation, viral oncoprotein association, and nuclear tethering. Proc. Natl. Acad. Sci. 88: 3033-3037.

Thalmeier, K., Synovzik, H., Mertz, R., Winnacker, E.L., and Lipp, M. 1989. Nuclear factor E2F mediates basic transcription and trans-activation by E1a of the human MYC promoter. Genes \& Dev. 3: 527-536.

Trouche, D., Cook, A., and Kouzarides, T. 1996. The CBP coactivator stimulates E2F1/DP1 activity. Nucleic Acids Res. 24: 4139-4145.

Trouche, D., Le, C.C., Muchardt, C., Yaniv, M., and Kouzarides, T. 1997. RB and hbrm cooperate to repress the activation functions of E2F1. Proc. Nat1. Acad. Sci. 94: 11268-11273.

Tsai, K.Y., Hu, Y., Macleod, K.F., Crowley, D., Yamasaki, L., and Jacks, T. 1998. Mutation of E2f-1 suppresses apoptosis and inappropriate $\mathrm{S}$ phase entry and extends survival of $\mathrm{Rb}$ deficient mouse embryos. Mol. Cell 2: 293-304.

Tyler, J.K. and Kadonaga, J.T. 1999. The "dark side" of chromatin remodeling: Repressive effects on transcription. Cell 99: 443-446.

Wallberg, A.E., Neely, K.E., Gustafsson, J.A., Workman, J.L., Wright, A.P., and Grant, P.A. 1999. Histone acetyltransferase complexes can mediate transcriptional activation by the major glucocorticoid receptor activation domain. Mol. Cell. Biol. 19: 5952-5959.

Weinberg, R.A. 1995. The retinoblastoma protein and cell cycle control. Cell 81: 323-330.

Weintraub, S.J., Prater, C.A., and Dean, D.C. 1992. Retinoblastoma protein switches the E2F site from positive to negative element. Nature 358: 259-261.

Weintraub, S.J., Chow, K.N., Luo, R.X., Zhang, S.H., He, S., and Dean, D.C. 1995. Mechanism of active transcriptional repression by the retinoblastoma protein. Nature 375: 812815.

Welch, P.J. and Wang, J.Y. 1993. A C-terminal protein-binding domain in the retinoblastoma protein regulates nuclear cAbl tyrosine kinase in the cell cycle. Cell 75: 779-790.

. 1995. Disruption of retinoblastoma protein function by coexpression of its C pocket fragment. Genes \& Dev. 9: 3146.

Whitaker, L.L., Su, H., Baskaran, R., Knudsen, E.S., and Wang, J.Y.J. 1998. Growth suppression by an E2F-binding-defective retinoblastoma protein $(\mathrm{RB})$ : Contribution from the RB C pocket. Mol. Cell. Biol. 18: 4032-4042.

Whyte, P., Buchkovich, K.J., Horowitz, J.M., Friend, S.H., Raybuck, M., Weinberg, R.A., and Harlow, E. 1988. Association between an oncogene and an anti-oncogene: The adenovirus E1A proteins bind to the retinoblastoma gene product. $\mathrm{Na}$ ture 334: 124-129.

Wolffe, A.P. and Hayes, J.J. 1999. Chromatin disruption and modification. Nucleic Acids Res. 27: 711-720.

Wu, C.L., Classon, M., Dyson, N., and Harlow, E. 1996. Expression of dominant-negative mutant DP-1 blocks cell cycle progression in $\mathrm{G}_{1}$. Mol. Cell. Biol. 16: 3698-3706.

Xiao, Z.X., Chen, J., Levine, A.J., Modjtahedi, N., Xing, J., Sellers, W.R., and Livingston, D.M. 1995. Interaction between the retinoblastoma protein and the oncoprotein $\mathrm{Mdm} 2 . \mathrm{Na}$ ture 375: 694-698.

$\mathrm{Xu}$, H.J., Xu, K., Zhou, Y., Li, J., Benedict, W.F., and Hu, S.X. 1994. Enhanced tumor cell growth suppression by an N-terminal truncated retinoblastoma protein. Proc. Natl. Acad. 
Sci. 91: 9837-9841.

Yee, A.S., Shih, H.H., and Tevosian, S.G. 1998. New perspectives on retinoblastoma family functions in differentiation. Front. Biosci. 3: D532-D547.

Zamanian, M. and La, T.N. 1993. Transcriptional repression by the Rb-related protein p107. Mol. Biol. Cell 4: 389-396.

Zhang, H.S., Gavin, M., Dahiya, A., Postigo, A.A., Ma, D., Luo, R.X., Harbour, J.W., and Dean, D.C. 2000. Exit from $\mathrm{G}_{1}$ and $\mathrm{S}$ phase of the cell cycle is regulated by repressor complexes containing HDAC-Rb-hSWI/SNF and Rb-hSWI/SNF. Cell 101: 79-89.

Zhang, H.S., Postigo, A.A., and Dean, D.C. 1999. Active transcriptional repression by the Rb-E2F complex mediates $G_{1}$ arrest triggered by p16INK4a, TGF $\beta$, and contact inhibition. Cell 97: 53-61.

Zhang, Y., Xiong, Y., and Yarbrough, W.G. 1998. ARF promotes Mmd2 degradation and stabilizes p53: ARF-INK4a locus deletion impairs both the $\mathrm{Rb}$ and $\mathrm{p} 53$ tumor suppression pathways. Cell 92: 725-734.

Zhu, J.W., DeRyckere, D., Li, F.X., Wan, Y.Y., and DeGregori, J. 1999. A role for E2F1 in the induction of ARF, p53, and apoptosis during thymic negative selection. Cell Growth Differ. 10: 829-838.

Zhu, L., Enders, G., Lees, J.A., Beijersbergen, R.L., Bernards, R., and Harlow, E. 1995a. The pRB-related protein p107 contains two growth suppression domains: Independent interactions with E2F and cyclin/cdk complexes. EMBO $I$. 14: 1904-1913.

Zhu, L., Harlow, E., and Dynlacht, B.D. 1995b. p107 uses a p21CIP1-related domain to bind cyclin/Cdk2 and regulate interactions with E2F. Genes \& Dev. 9: 1740-1752.

Zhu, L., van den Heuvel, S., Helin, K., Fattaey, A., Ewen, M., Livingston, D., Dyson, N., and Harlow, E. 1993. Inhibition of cell proliferation by 107 , a relative of the retinoblastoma protein. Genes \& Dev. 7: 1111-1125. 


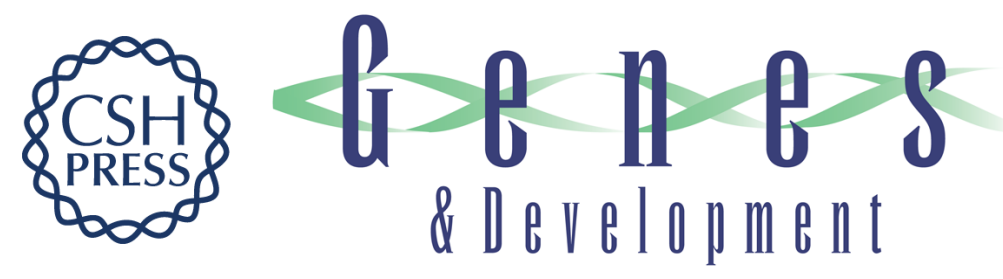

\section{The Rb/E2F pathway: expanding roles and emerging paradigms}

J. William Harbour and Douglas C. Dean

Genes Dev. 2000, 14:

Access the most recent version at doi:10.1101/gad.813200

References This article cites 171 articles, 90 of which can be accessed free at: http://genesdev.cshlp.org/content/14/19/2393.full.html\#ref-list-1

License

Email Alerting Receive free email alerts when new articles cite this article - sign up in the box at the top Service right corner of the article or click here.

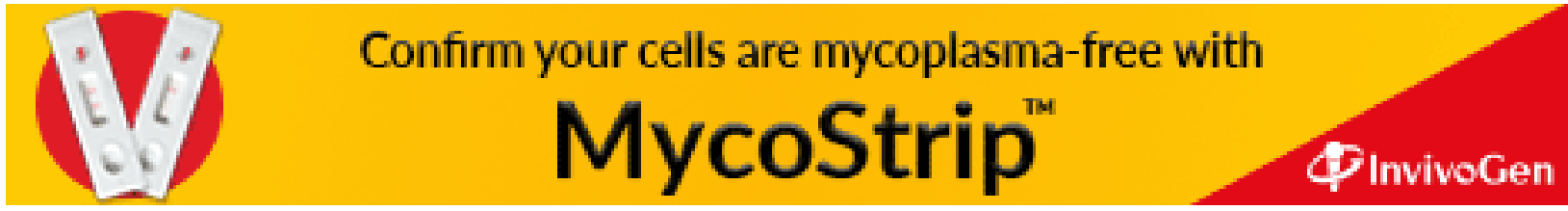

